\title{
Radio over Fiber Based Spectrally Encoded OCDM To Support 5G \& Beyond 5G Mobile Fronthaul Network Challenges
}

Brindha Saminathan ( $\sim$ brindhamit@gmail.com )

Sri sairam Engineering college,Chennai. https://orcid.org/0000-0002-6141-1589

T. llavarasan

Vellore Institute of Technology: VIT University

Meenakshi M

Anna University Chennai

T. Sivasakthi

Sri Sai Ram Engineering College

Maria Christina Blessy

St Joseph's Institute of Technology

K. Devibalan

Sri Sai Ram Engineering College

G. Lakshmi

Sri Sai Ram Engineering College

\section{Research Article}

Keywords: Green communication, Energy efficiency, electromagnetic pollution, fronthaul, multi-operator multi-service, link budget, radio over fiber

Posted Date: April 19th, 2021

DOI: https://doi.org/10.21203/rs.3.rs-395780/v1

License: (c) (i) This work is licensed under a Creative Commons Attribution 4.0 International License. Read Full License 


\title{
Radio over Fiber Based Spectrally Encoded OCDM To Support 5G \& Beyond 5G Mobile Fronthaul Network Challenges
}

\author{
Dr. S.Brindha, Dr.T.Ilavarasan , Dr.M.Meenakshi,T.Sivasakthi, A.Maria Christina \\ Blessy,K.Devibalan \&G.Lakshmi
}

\begin{abstract}
Multi-operator Multi-Service support over mobile fronthaul network would be an important requirement in the evolving $5 G$ Wireless Communication architectures. This in turn dictates the need for high capacity and high connectivity fronthaul options. Optical Code Division Multiplexing over Wavelength Division Multiple Access could be one of the most promising system architectures to support last/first mile bottleneck of the Mobile Networks. This paper reports comparison impact of the energy efficiency and electromagnetic radiation effects for a multi-operator multi-service OCDM based Spectrally Amplitude Encoded Analog Radio over Fiber front-haul for a small cell configuration. The WDM multiplexed mm wave signals at $60 \mathrm{GHz}$ and $28 \mathrm{GHz}$ and Prime code based spectral amplitude patterns assigned for conventional services are analyzed and compared with Wavelength Division Multiple Access system of the same kind. The comparison results confirms that proposed architecture will be a suitable candidate to meet $5 G$ challenges of Mobile fronthaul Networks.
\end{abstract}

Index Terms - Green communication, Energy efficiency, electromagnetic pollution, fronthaul, multi-operator multi-service, link budget, radio over fiber.

\section{INTRODUCTION}

The evolving trend in the next generation of wireless communication suggests the increasing necessity for integrating the different communication architectures, transport options and switching technologies, to support the

*Dr S.Brindha, Professor, Dept. of ECE, Sri Sairam Engineering college, Chennai-44 (e-mail: sbrindha.ece @ sairam.edu.in. \& brindhamit@gmail.com) Tamil Nadu, India.

Dr. T.Ilavarasan , Assistant Professor, Dept. of ECE, VIT (e-mail: ila.ece @ gmail.com.) Tamil Nadu, India,

Dr M.Meenakshi Professor , Department of Electronics and Communication Engineering, Anna University Chennai, Guindy campus, Chennai -600025;(e-mail: meena68@ annauniv.edu), India.

T.Sivasakthi, Assistant Professor, Dept. of ECE, Sri Sairam Engineering college, Chennai-44 (e-mail: sivasakthi.ece @ sairam.edu.in.) Tamil Nadu, India.

A.Maria Christina Blessy, Assistant Professor St. Joseph's Institute of Technology blessysjit@gmail.com, Tamil Nadu, India.

K.Devibalan, Assistant Professor, Dept. of ECE, Sri Sairam Engineering college, Chennai-44 (e-mail: devibalan.ece @ sairam.edu.in.) Tamil Nadu, India.

G.Lakshmi, Assistant Professor, Dept. of ECE, Sri Sairam Engineering college, Chennai-44 (e-mail: lakshmig.ece @ sairam.edu.in.) Tamil Nadu, India. growing demand in the number of Internet users, bandwidthintense applications and the Internet of Things (IoT). Radio architecture is now evolving to provide operators with enhanced flexibility, capacity, coverage and scalability $[1,2]$. Commercial mobile broadband networks are undergoing a dramatic transformation in their topology by implementing public access small cells which are the key for the future. Though growth in demand is often cited as the key driver for small cells to provide increased capacity, technology is also approaching efficiency limits. In order to support the highcapacity users in the densely populated urban zone, many small cells [3] need to be located to provide coverage.

The phenomenal growth of wireless connectivity is made possible today at the expense of considerable energy consumption, which in turn adds to carbon dioxide $\left(\mathrm{CO}_{2}\right)$ emission and global warming problems [4]. With the advent of data intensive cellular standards, power-consumption for each base station can increase up to 1,400 watts and energy costs per base station can reach to $\$ 3,200$ per annum with a carbon footprint of 11 tons of $\mathrm{CO}_{2}$ [5].

The rapidly growing demand for mobile communication technology has resulted in an exponential increase in the number of cellular BSs worldwide from a few hundred thousand to many millions within the last couple of years. Such a substantial jump in the number of BSs that power a cellular network accounts for the sudden increase in Green House Gases (GHG) and pollution, in addition to higher energy costs to operate them [6]. Recently, there is also an ongoing debate about the associated health risk due to radiation from mobile equipment and BS towers [7] Interphone study in 2010 mentions that excessive use of mobile phones has doubled to quadrupled brain tumor risk [8]. So it is crucial to reduce the power consumed and as well as the power radiated from the cellular networks [9].

The power amplifiers and the climate control units present in the base station (BS) of cellular network consume more than $60 \%$ of the energy. A network architecture needs to be evolved in such a way as to avoid the usage of PAs. Small cell network (SCN) approach implemented with RoF based fronthaul is expected to significantly reduce energy needs and the electromagnetic field exposure to the mobile user and his immediate neighbors as well as a larger pollution closer to the BS tower [10,11]. The other factors driving operators to 
deploy small cells, are their deployment styles and the type of backhaul and fronthaul requirements.

The exploration of higher RF bands, especially at the millimeter-wave (mm Wave) band (30 GHz-300 GHz), has attracted huge attention from both industries and academia for their high bandwidth support. The combination of mmWave radio and small-cell architecture [3] provides a promising solution for next-generation very-high-speed wireless access networks. The main challenge is the RoF interface design to support mmWave services as well as backward compatibility to legacy wireless services.

Migrating to optical backhauling and fronthauling along with the adoption of small cell architecture is the way forward over the long-term solution to reduce GHG emissions, since optical communications devices consume less energy than electronic ones. Network devices can also be designed with features that create an opportunity for energy-saving operation such as turning off network interfaces and throttling of processors. The currently deployed fronthaul links are based on the Common Public Radio Interface (CPRI) protocol or the Open Base Station Architecture (OBSAI) Interfaces [12, 13, and 14]. The link supports digitized IQ samples of the radio signal along with suitable preambles and control information. The challenge in this approach is the scalability in link capacity to support multiplexed signals from larger number of remote antenna systems. This constraint is even more stringent when multiple radio services or multiple operator's signals need to be simultaneously transmitted over the fiber fronthaul.

Analog radio-over-fiber (ARoF) method enables multi-service multi-operator coexistence in a shared infrastructure with simplified RAUs whereas the conventional digital-baseband-transmission approach typically supports only one service at a time. In addition, it is beneficial to integrate with optical wavelength division multiplexing (WDM) techniques to provide more versatility and flexibility to the fronthaul/backhaul networks. Such a system provides multiple operational advantages such as:

1.Multiple operators can co-exist in a shared small-cell infrastructure by using different WDM wavelengths.

2.Within each operator, different wireless services can copropagate in the RoF fronthaul/backhaul in a simplified way.

3.For each wireless service, multiple MIMO data streams and multiple sub-bands can also coexist in the RoF link without incurring undesirable interference.

4.Multiple operators, multiple services, and multiple wireless techniques can share the same small-cell infrastructure while maintaining independent configurability through the centralized management [15].

WDMA networks require stringent control over the optical wavelength spacing and filter bandwidth to accommodate individual operators/services on uniquely allocated optical channels. Moreover, the available wavelength resource in mainstream WDMA systems is also limited and there is a need to find alternate approaches for sharing the available spectrum without affecting the achievable bit rate. Hence WDM cannot be brought down to the customer premises of small-to-medium sized businesses and residential users. Optical code division multiplexing (OCDM) layer over WDMA provides a possible solution.
OCDM can provide access to connections on demand simultaneously, multiplexed at the same wavelength channel through unique signature codes [16, 17]. Such an OCDM option is explored in this paper to support multiple- operator multi-service provisioning using ARoF fronthaul.

Jian-Guo Zhang et al [18] proposed an Integrated Services Digital Broadcasting (ISDN) system employing a multi-rate optical code-division multiplexing technique in which unique one-dimensional optical orthogonal codes (OOCs) were used to represent the services. The authors using analytic and experimental results, concluded that the system can support Fast Ethernet upto $125 \mathrm{Mb} / \mathrm{s}$, FDDI upto $125 \mathrm{Mb} / \mathrm{s}$, ATM upto $155 \mathrm{Mb} / \mathrm{s}$ and ESCON upto $200 \mathrm{Mb} / \mathrm{s}$ protocol data. Since OCDMA technology can implement multiple asynchronous access at random and flexible diversity of encoding, in addition to effectively supporting data network, many types of media such as voice, data, image and video, can be sustained in the communication link by the flexible network design and variety of choices of OCDMA systems.

Yang \& Kwong [19] proposed a kind of OCDMA network that provides appropriate quality of services (QoS) for different subscribers. For example, different service demands from different subscribers can be satisfied by encoding high-rate services with short code and low-rate services with long code, services with high QoS by codes with high performance and low QoS by codes with low performance codes.

ARoF system based on OCDMA multiplexing method was proposed in [20] in which the theoretical analysis and experimental demonstration were conducted. The unipolar prime code was employed in this system and the results reveal that the proposed scheme is effective. Also it was shown in theory that the number of maximum connected RBSs could be further improved by employing bipolar pseudo noise (PN) codes.

The main difference between the proposed paper and the previously published paper which we have cited in the reference section [Ref.no:40] is as follows:

1. Optical Code Division Multiplexing (OCDM) over Wavelength Division Multiple Access (WDMA) could be one of the most promising system architectures that can break through the last/first mile bottleneck of the Mobile Networks.

2. WDMA networks, which uniquely assign a wavelength to each user, can accommodate only a moderate number of users/operators/services.

3. Spectrally encoded OCDM can provide an additional degree of freedom by allowing multiple access connections simultaneously on a single WDMA channel. Multiple users of a single service/ multiple services of a single operator can be multiplexed on the same wavelengths through unique spectral signature patterns.

4. In the WDMA based MOMS-AROF architecture [40] conventional services like GSM, LTE and WLAN, are multiplexed and Externally modulated at the same wavelength whereas in the proposed SAC-OCDM architecture exclusive patterns based on unique Prime 
codes are assigned for each service like GSM, LTE and WLAN, encoded and multiplexed at the same wavelength.

5. The usage of unique Prime codes (SAC-OCDM) reduces the system cost for multiple services of a single operator / handling of multiple users of a single service instead of allocating wavelengths (MOMS-AROF case).

The results of both system architectures suggests that the possibility of eliminating the energy consuming power amplifiers (PA) in the transceivers in order to achieve a reduced electromagnetic pollution in the environment, so MOMS-AROF can be replaced by SAC-OCDM to reduce the system cost.

The rest of the paper is organized as follows. In Section II, SAC-OCDM architecture is discussed with 5 different services. In Section III, Prime codes for SAC-OCDM is explored with respect to multiservice. Section IV, presents in detail the link performance analysis and discussion. In Section V, the Link power budget, Energy considerations and BER analysis for each service separately and then compared with WDM backbone with appropriately assumed parameters. Finally, the conclusions are highlighted in section VI.

\section{SAC- OCDM ARCHITECTURE}

The Small Cells based Cloud RoF architecture is depicted in Fig. 1.

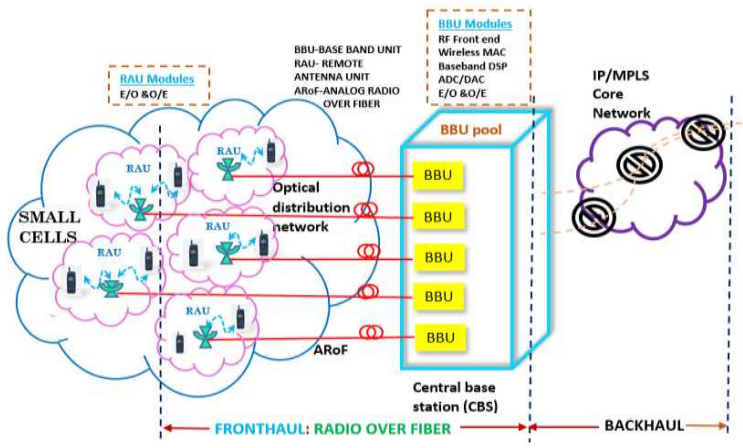

Fig. 1. Architecture of Small cell based Cloud - RoF

The multi-operator multi-service analog radio over fiber (SAC-OCDM) integrated architecture in a heterogeneous cellular configuration is shown in Fig. 2. The conventional wireless services such as GSM, LTE and WLAN utilizing SAC OCDM coexist with $\mathrm{mm}$ wave band signals at $28 \mathrm{GHz}$ and $60 \mathrm{GHz}$. At the Central Base Station (CBS), the conventional RF carrier signals representing multiservice like 1.8GHz GSM, 2.6 GHz LTE and 5.0GHz WLAN from core networks is processed and encoded using SAC OCDM techniques with unique spectral pattern [22] based on prime codes (PC).

This integrated system incorporating SAC-OCDM along with WDMA for multiservice in the Radio over fiber system affords flexible configuration for each service independently.
The multiple spectral components needed for SAC OCDM are derived from a broadband coherent source are listed in Table I.

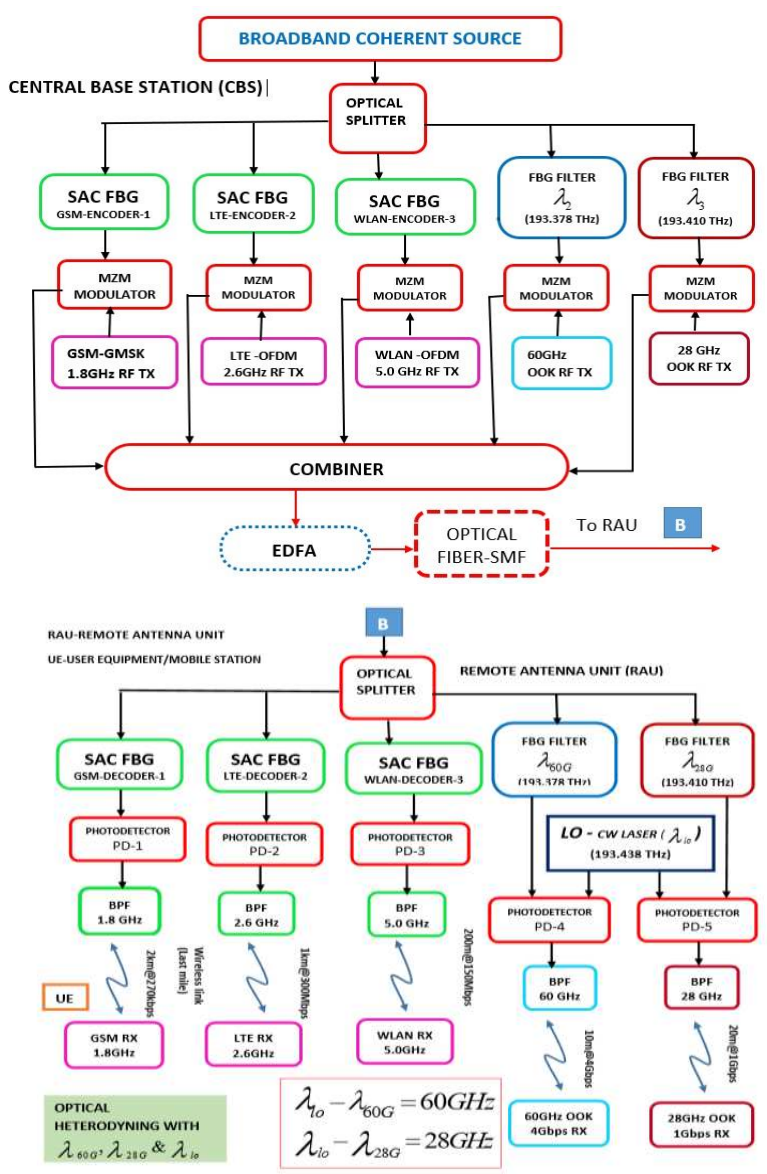

Fig. 2. System block diagram of SAC -OCDM

The optical signal emitted from a coherent broadband light source is split into multiple copies for the multiple services [23]. In this case super gaussian Laser source with RIN value of $-150 \mathrm{~dB} / \mathrm{Hz}$ is considered to carry on the Simulation work. The spectral components corresponding to the specific SAC pattern assigned for each service with code length $n=25$ is chosen based on prime codes (PC) and the encoding process is carried out by employing the FBGs [24, 25]. In doing so, the spectral amplitude encoding based on FBGs for each service is achieved [26, 27 \& 28]. With assigned prime code pattern, suitable number of FBGs are used to get the wavelength pattern for each of the proposed service with the FBG having notch filter super gaussian order of ' 1 ' and two-sided bandwidth $(-3 \mathrm{~dB})$ of $0.1 \mathrm{GHz}(0.008 \mathrm{~nm})$ specifications.

Three properties that need to be controlled in an FBG are the reflectivity, the bandwidth and the side-lobe strength. The side-lobe strength can be varied to help with side-lobe suppression called apodization of the refractive index change. Apodised gratings offer significant improvement in side-lobe suppression while maintaining reflectivity and a narrow bandwidth. The two functions typically used to apodize an FBG are Gaussian and raised-cosine. The numerical 
parameters used in the link simulation study are listed in Table II.

TABLE I SPECTRAL COMPONENTS FOR N=25

\begin{tabular}{|c|c|c|c|}
\hline $\begin{array}{l}\text { S. } \\
\text { No. }\end{array}$ & $\begin{array}{l}\text { Multi wavelength } \\
\text { source } n=25\end{array}$ & $\begin{array}{l}\text { S. } \\
\text { No. }\end{array}$ & $\begin{array}{l}\text { Multi wavelength } \\
\text { source } n=25\end{array}$ \\
\hline 1. & $\lambda_{0}=193.383 \mathrm{THz}$ & 13. & $\lambda_{12}=193.417 \mathrm{THz}$ \\
\hline 2. & $\lambda_{1}=193.386 \mathrm{THz}$ & 14. & $\lambda_{13}=193.420 \mathrm{THz}$ \\
\hline 3. & $\lambda_{2}=193.389 \mathrm{THz}$ & 15. & $\lambda_{14}=193.423 \mathrm{THz}$ \\
\hline 4. & $\lambda_{3}=193.391 \mathrm{THz}$ & 16. & $\lambda_{15}=193.426 \mathrm{THz}$ \\
\hline 5. & $\lambda_{4}=193.394 \mathrm{THz}$ & 17. & $\lambda_{16}=193.429 \mathrm{THz}$ \\
\hline 6. & $\lambda_{5}=193.397 \mathrm{THz}$ & 18. & $\lambda_{17}=193.432 \mathrm{THz}$ \\
\hline 7. & $\lambda_{6}=193.400 \mathrm{THz}$ & 19. & $\lambda_{18}=193.435 \mathrm{THz}$ \\
\hline 8. & $\lambda_{7}=193.403 \mathrm{THz}$ & 20. & $\lambda_{19}=193.438 \mathrm{THz}$ \\
\hline 9. & $\lambda_{8}=193.406 \mathrm{THz}$ & 21. & $\lambda_{20}=193.440 \mathrm{THz}$ \\
\hline 10. & $\lambda_{9}=193.409 \mathrm{THz}$ & 22. & $\lambda_{21}=193.443 \mathrm{THz}$ \\
\hline 11. & $\lambda_{10}=193.412 \mathrm{THz}$ & 23. & $\lambda_{22}=193.446 \mathrm{THz}$ \\
\hline \multirow[t]{2}{*}{12.} & $\lambda_{11}=193.414 \mathrm{THz}$ & 24. & $\lambda_{23}=193.449 \mathrm{THz}$ \\
\hline & & 25. & $\lambda_{24}=193.452 \mathrm{THz}$ \\
\hline
\end{tabular}

\begin{tabular}{|c|c|}
\hline PARAMETERS & VALUE \\
\hline $\begin{array}{l}\text { Broadband source emission } \\
\text { wavelength range }\end{array}$ & $1549.47927 \mathrm{~nm}-1550.52 \mathrm{~nm}$ \\
\hline $\begin{array}{l}\text { Broadband source emission } \\
\text { frequency range }\end{array}$ & 193.34949THz - 193.47949THz \\
\hline $\begin{array}{l}\text { Operator-1 - Service 1-GSM } \\
\text { signal (at CBS)-Prime code } \\
\text { Spectral pattern(from } \\
\text { Broadband source) } \\
\end{array}$ & $\begin{array}{l}\mathbf{P C}_{0}=(00000) \\
\quad=\lambda_{0} \lambda_{5} \lambda_{10} \lambda_{15} \lambda_{20} \\
=\lambda_{0} 0000 \lambda_{5} 0000 \quad \lambda_{10} 0000 \lambda_{15} 0000 \lambda_{20} 0000\end{array}$ \\
\hline $\begin{array}{l}\text { Operator-1 - Service } 2 \text {-LTE } \\
\text { signal(at CBS)- Prime code } \\
\text { Spectral pattern(from } \\
\text { Broadband source) }\end{array}$ & $\begin{array}{l}\mathbf{P C}_{1}=(01234) \\
=\lambda_{0} \lambda_{8} \lambda_{12} \lambda_{18} \lambda_{24} \\
=\lambda_{0} 0000 \quad 0 \lambda_{8} 000 \quad 00 \lambda_{12} 00 \quad 000 \lambda_{18} 00000 \lambda_{24}\end{array}$ \\
\hline $\begin{array}{l}\text { Operator-1 - Service 3 -WLAN } \\
\text { signal(at CBS)- Prime code } \\
\text { Spectral pattern(from } \\
\text { Broadband source) }\end{array}$ & $\begin{array}{l}\mathbf{P C}_{2}=(02413) \\
=\lambda_{0} \lambda_{7} \lambda_{14} \lambda_{16} \lambda_{23} \\
=\lambda_{0} 0000 \quad 00 \lambda_{7} 00 \quad 0000 \lambda_{14} 0 \lambda_{16} 000 \quad 000 \lambda_{23} 0\end{array}$ \\
\hline Operator-2 - $\lambda_{60 G}$ (at CBS) & $1550.29247 \mathrm{~nm}(193.378 \mathrm{THz})$ \\
\hline Operator-3 - $\lambda_{28 G}$ (at CBS) & $1550.03598 \mathrm{~nm}(193.410 \mathrm{THz})$ \\
\hline Local Oscillator- $\lambda_{i 0}$ (at RAU) & 1549.8116lnm (193.438THz) \\
\hline$\lambda_{10}-\lambda_{60 G}($ Heterodyne at PD $)$ & $60 \mathrm{GHz}$ \\
\hline$\lambda_{i 0}-\lambda_{28 G}$ (Heterodyne at PD) & 28GHz \\
\hline Service 1-GSM signal & 1.8GHz-270Kbps-GMSK \\
\hline Service 2 -LTE signal & 2.6GHz-300Mbps-4QAM- OFDM \\
\hline Service 3 -WLAN signal & 5.0GHz-150Mbps- 4-QAM-OFDM \\
\hline Service 4-Small cell- Wi-Gig & $60.0 \mathrm{GHz}-4.0 \mathrm{Gpbs}-\mathrm{OOK}-\mathrm{mm}$ wave \\
\hline Service 5-Small cell- LMDS & 28.0GHz-1.0Gpbs- OOK-mm wave \\
\hline $\begin{array}{l}\text { Fiber length between CBS \&RAU } \\
\text { (SMF) }\end{array}$ & $\sim 25 \mathrm{~km}$ \\
\hline Distance between RAU \&UE & $\begin{array}{l}\sim 10 \mathrm{~m}-20 \mathrm{~m}-\text { Small cell } \\
\sim 200 \mathrm{~m}-W \mathrm{WAN} \\
\sim \text { Up to } 1 \mathrm{~km}-\mathrm{LTE} \\
\sim \mathrm{Up} \text { to } 2 \mathrm{~km}-\mathrm{GSM}\end{array}$ \\
\hline Fiber dispersion(D) & $16 \mathrm{ps} / \mathrm{nm} / \mathrm{km}$ \\
\hline Fiber loss & $0.2 \mathrm{~dB} / \mathrm{km}$ \\
\hline Receiver sensitivity & $-36.0 \mathrm{dBm}$ \\
\hline Receiver Responsivity & $0.8 \mathrm{~A} / \mathrm{W}$ \\
\hline Channel type & AWGN(Rayleigh fading) \\
\hline
\end{tabular}

External modulation in optical domain is usually achieved with the help of MZM device wherein one of the inputs is the user information (GSM, LTE, WLAN or mm wave signals) and the second input is the laser signal from broad Coherent laser source with specific spectral pattern generated using FBG. The MZM having extinction ratio of $20.0 \mathrm{~dB}$, Vpi value of $5.0 \mathrm{~V},(-3 \mathrm{~dB})$ bandwidth of $10.0 \mathrm{GHz}$ and average power reduction due to power modulation is around $3 \mathrm{~dB}$ is proposed for simulation in this case.
The GSM signal is generated with suitable RF source of $1.8 \mathrm{GHz}$ carrier signal which is suitably gaussian shift keying (GMSK) modulated and then intensity modulated with MZM in which the second input is the spectral pattern generated with the help of FBG for the GSM signal. Then the externally modulated signal is routed to the WDM multiplexer for further transmission. The LTE and WLAN signals are OFDM modulated with suitable RF source of $2.6 \mathrm{GHz}$ carrier signal \& $5.0 \mathrm{GHz}$ carrier signal respectively and then intensity modulated with MZM in which the second input is spectral pattern generated using prime code with the help of FBG for the LTE signal\& WLAN signal.

The GSM signal is externally MZM modulated with a $\left[\lambda_{0} 0000 \lambda_{5} 0000 \lambda_{10} 0000 \lambda_{15} 0000 \lambda_{20} 0000=\left(\lambda_{0} \lambda_{5} \lambda_{10} \lambda_{15} \lambda_{20}\right)\right]$ specific spectral pattern with indexed wavelengths as specified in the Table 1. The procedure is repeated for LTE and WLAN with

$$
\begin{aligned}
& {\left[\begin{array}{lllll}
\lambda_{0} 0000 & 0 \lambda_{6} 000 & 00 \lambda_{12} 00 & 000 \lambda_{18} 0 & 0000 \lambda_{24}=\left(\lambda_{0} \lambda_{6} \lambda_{12} \lambda_{18} \lambda_{24}\right)
\end{array}\right] \&} \\
& {\left[\begin{array}{llll}
\lambda_{0} 0000 & 00 \lambda_{7} 00 & \left.0000 \lambda_{14} 0 \lambda_{16} 000000 \lambda_{23} 0=\left(\lambda_{0} \lambda_{7} \lambda_{14} \lambda_{16} \lambda_{23}\right)\right],
\end{array}\right.}
\end{aligned}
$$

respectively. In doing so, the spectral amplitude encoding based on FBGs for each service is achieved [26, $27 \& 28]$.

The $60 \mathrm{GHz}$ and $28 \mathrm{GHz}$ data services offered by operator 2 and operator 3 use baseband on off Keying (OOK) modulation and intensity modulate the wavelengths $\lambda_{60 \mathrm{G}}$ (193.378THz) and $\lambda_{28 G}(193.410 \mathrm{THz})$ respectively. A typical digital fiber transmission system makes use of the simplest method called Amplitude Shift Keying (ASK) or On-Off Keying (OOK) technique wherein the voltage level is switched between two values that is ON and OFF to send digital message pulses i.e., the optical signal emerging from the transmitter binary 1 represented by a presence of light pulse and binary 0 by absence of light pulse. This kind of simple modulation technique is implemented for $\mathrm{mm}$ wave signals like $60 \mathrm{GHz}$ and $28 \mathrm{GHz}$ to keep the system cost effective.

The WDM multiplexed mm wave signals and the three spectrally encoded conventional signals are combined in an optical star coupler and transmitted through $25 \mathrm{~km}$ standard single mode fiber (SMF) connected between CBS and the RAUs. To keep the system simple and cost effective the compensation of any optical domain impairment has to be done in the electronic domain with suitable signal processing adaptively depending on the necessity.

At the Remote antenna Unit (RAU) the signals would be wavelength de-multiplexed. The conventional wireless service signals are properly decoded using the assigned spectral pattern in their respective decoding units and then detected by a PIN photo detector (PD) receiver with a sensitivity of $36 \mathrm{dBm}$ [29] for an allowed error probability $10^{-9}$. By proper selection of wavelengths, the crosstalk term will fall beyond the electrical bandwidth of receiver PD.

High performance Photodetectors are used in the proposed system which are capable of handling more than two 
signals at a time for detection process. Allowed value lies between $0 \sim 1$ and the default value are 0.75 . The responsivity is related to quantum efficiency. Hence the present approach for sharing channel resource enables infrastructure sharing among multiple operators without interference. A single PD has power constraint of detecting signals on multiple wavelengths and hence the number of operators to share a single PD is limited [15]. After Photo detection the multiple $\mathrm{RF}$ signals on different carrier frequencies like 1.8, 2.6 and $5.0 \mathrm{GHz}$ are filtered out using suitable band pass filters (BPF) and transmitted wirelessly to mobile users (MU). The signals on wavelengths $\lambda_{60 G}$ and $\lambda_{28 G}$ would coherently beat with a local optical source at wavelength $\lambda_{l o}$ in their respective PDs, to generate the OOK modulated $\mathrm{mm}$ wave signals at $60 \mathrm{GHz}$ and $28 \mathrm{GHz}$, respectively. The feasibility of such an approach has been reported in [29].

The last mile connectivity between RAU and UE varies for different services based on the data rate supported by that specific service. In the present work, GSM service with minimum last mile wireless connectivity of $2 \mathrm{~km}$ with data rate of $270 \mathrm{kbps}$ (a single user), LTE user with last mile connectivity of $1 \mathrm{~km}$ with data rate of $300 \mathrm{Mbps}$, WLAN user with last mile connectivity of $200 \mathrm{~m}$ with data rate of $150 \mathrm{Mbps}$, LMDS user with last mile connectivity of $20 \mathrm{~m}$ with data rate of $1.0 \mathrm{Gbps}$ and Wi-Gig user with last mile connectivity of $10 \mathrm{~m}$ with data rate of $4 \mathrm{Gbps}$, is considered for the simulation study of multiservice operation and then justified with suitable wireless power budget analysis discussed in section $\mathrm{V}$.

At UE the received analog signal is then detected with respective demodulator circuits and the BER estimated. The good quality of service is achieved with the specifications considered for all five services and different operators. A detailed power budget analysis is also done for all the services to determine energy efficiency and a quantitative estimate for the possible electromagnetic pollution and discussed in section V.

\section{PRIME CODES FOR SAC- OCDM}

The construction of a prime code (PC) is carried out as in [19]. Firstly, choose $d$ as a prime number and based on Galois field $\boldsymbol{G} \boldsymbol{F}(\boldsymbol{d})$, construct a prime sequence

$$
\begin{gathered}
P C_{i}=\left(p_{i, 0}, p_{i, 1}, p_{i, 2} \ldots, p_{i, j}, \ldots, p_{i,(d-1)}\right), \\
\boldsymbol{i}=\mathbf{O}, \mathbf{1}, \mathbf{2}, \ldots, \boldsymbol{d}-\mathbf{1}
\end{gathered}
$$

Where the element in this prime sequence is

$$
p_{i, j}=\{i \cdot j\}(\bmod d)
$$

$p_{i, j}, i \& j$ are the elements over the

Galois field $G F(d)=(0,1,2, \ldots, d-1)$
Then with the prime sequence

$C_{i, k}=\left\{\begin{array}{l}1 \text { If } k=p_{i, j}+j . w, \text { for } j=(0,1,2, \ldots d-1) \\ 0 \text { Otherwise }\end{array}\right.$

A binary prime code can be obtained as follows

$C_{i}=\left(c_{i, 0}, c_{i, 1}, \ldots, c_{i, k}, \ldots, c_{i,(n-1)}\right)$,

$i=0,1,2, \ldots, d-1, n=d^{2}$

The code length and code weight of the prime code are $n$ $=d^{2}$ and $w=d$ respectively. Maximum autocorrelation side lobe and maximum cross-correlation value for this code are $\lambda_{a}=d-1$ and $\lambda_{c}=2$ respectively [30]. The cardinality of PC is $|C|=d$. According to the definition of optical orthogonal code, $\mathrm{PC}$ is a quasi-OOC with the parameters $\left(n, d, \lambda_{a}, \lambda_{c}\right)=\left(d^{2}, d, d-1,2\right)$. The prime sequence $P C_{i}$ and the prime code $C_{i}$ constructed assuming $d=5$ are shown in Table III \& Table IV.

TABLE III

THE PRIME CODE SEQUENCE

\begin{tabular}{|c|lllll|}
\hline Elements of GF(5) & 0 & 1 & 2 & 3 & 4 \\
\hline$P C_{0}$ & 0 & 0 & 0 & 0 & 0 \\
\hline$P C_{1}$ & 0 & 1 & 2 & 3 & 4 \\
\hline$P C_{2}$ & 0 & 2 & 4 & 1 & 3 \\
\hline$P C_{3}$ & 0 & 3 & 1 & 4 & 2 \\
\hline$P C_{4}$ & 0 & 4 & 3 & 2 & 1 \\
\hline
\end{tabular}

TABLE IV

\begin{tabular}{|c|c|}
\hline Prime sequence $P C_{t}$ & Prime code $C_{i}$ \\
\hline $\begin{aligned} P C_{0} & =(00000) \\
& =\left(\lambda_{0} \lambda_{5} \lambda_{10} \lambda_{15} \lambda_{20}\right)\end{aligned}$ & $\begin{array}{ccccc}10000 & 10000 & 10000 & 10000 & 10000 \\
\lambda_{0} 0000 & \lambda_{5} 0000 & \lambda_{10} 0000 & \lambda_{15} 0000 & \lambda_{20} 0000\end{array}$ \\
\hline $\begin{aligned} P C_{1} & =(01234) \\
& =\left(\lambda_{0} \lambda_{6} \lambda_{12} \lambda_{18} \lambda_{24}\right)\end{aligned}$ & $\begin{array}{lllll}10000 & 01000 & 00100 & 00010 & 00001 \\
\lambda_{8} 0000 & 0 \lambda_{6} 000 & 00 \lambda_{12} 00 & 000 \lambda_{18} 0 & 0000 \lambda_{24}\end{array}$ \\
\hline $\begin{aligned} P C_{2} & =(02413) \\
& =\left(\lambda_{0} \lambda_{7} \lambda_{14} \lambda_{16} \lambda_{23}\right)\end{aligned}$ & $\begin{array}{lllll}10000 & 00100 & 00001 & 01000 & 00010 \\
\lambda_{0} 0000 & 00 \lambda_{7} 00 & 0000 \lambda_{14} & 0 \lambda_{10} 000 & 000 \lambda_{23} 0\end{array}$ \\
\hline $\begin{aligned} P C_{3} & =(03142) \\
& =\left(\lambda_{0} \lambda_{3} \lambda_{11} \lambda_{19} \lambda_{22}\right)\end{aligned}$ & $\begin{array}{lllll}10000 & 00010 & 01000 & 00001 & 00100 \\
\lambda_{0} 0000 & 000 \lambda_{8} 0 & 0 \lambda_{11} 000 & 0000 \lambda_{19} & 00 \lambda_{22} 00\end{array}$ \\
\hline $\begin{aligned} P C_{4} & =(04321) \\
& =\left(\lambda_{0} \lambda_{9} \lambda_{13} \lambda_{17} \lambda_{21}\right)\end{aligned}$ & $\begin{array}{lllll}10000 & 00001 & 00010 & 00100 & 01000 \\
\lambda_{2} 0000 & 0000 \lambda_{9} & 000 \lambda_{13} 0 & 00 \lambda_{17} 00 & 0 \lambda_{21} 000\end{array}$ \\
\hline
\end{tabular}

SPECTRAL PATTERN FOR PRIME CODES $C_{i}$ CONSTRUCTED FOR $n=d^{2}$

From Table III \& Table IV, it can be seen that each code word in a prime code can be divided into $d$ subsets with the length $d$ for each subset. There is exactly one " 1 " in each 
subset and the position of this "1" is determined by the element in the corresponding prime sequence. The advantage of the prime code is that its generation algorithm is very simple and the shortcomings are that it has larger autocorrelation side lobes equal to $d-1$, its cross-correlation is not always equal to 1 and the cardinality of the prime code is only equal to its weight. In this work perfect code synchronization is assumed so that the correlation issues are reduced and the cardinality is not a major issue because of considering only lesser number of services.

\section{SAC - OCDM LINK PERFORMANCE ANALYSIS AND VALIDATION}

To validate and analyze the feasibility of the proposed architecture simulations are performed using RSoft-OptsimV2015.06 [31]. With the help of quasi analytical method the parameters bit error-rate (BER) and error vector magnitude (EVM) calculations are carried out. The minimum transmit power requirement to achieve a BER value of $10^{-9}$ to $10^{-12}$ at the RAU with fiber length of $25 \mathrm{~km}$ for all proposed services along with the required receiver sensitivity are derived from the simulations carried out .

The overall emission spectrum of broadband coherent source is depicted in Fig. 3(a) where only 25 wavelengths $\left(\lambda_{0} \ldots \lambda_{24}\right)$ from $193.383 \mathrm{THz}$ to $193.452 \mathrm{THz}$ are considered to represent the prime code for different services. The range of spectral code pattern $\left(\lambda_{0} \lambda_{5} \lambda_{10} \lambda_{15} \lambda_{20}\right)$ representing unique prime code for GSM signal of operator-1 derived from broadband coherent source at CBS is depicted in Fig. 3. (b). similarly for LTE signal of operator-1 spectral code pattern $\left(\lambda_{0} \lambda_{6} \lambda_{12} \lambda_{18} \lambda_{24}\right)$ and WLAN signal of operator-1 spectral code pattern $\left(\lambda_{0} \lambda_{7} \lambda_{14} \lambda_{16} \lambda_{23}\right)$ are depicted in Fig.3(c) \& (d), respectively.

Each of the conventional services of operator-1 is analyzed and compared using SAC-OCDM technique based on prime codes. The downstream data rates range from $270 \mathrm{Kbps}$ to $300 \mathrm{Mbps}$ for the 3 services considered. The transmitting power at central base station (CBS) varies from $-30 \mathrm{dBm}$ to about $40 \mathrm{dBm}$ for the 3 services by all three operators. The downstream traffic signal to noise ratio (SNR) for each service at PD output at RAU is evaluated and the corresponding EVM values are estimated using the SNR for both, the back to back link and the $25 \mathrm{~km}$ SMF link. The transmitted optical power is varied and performance analyzed for each conventional services of operator -1 and plotted in Fig.4. (a). In each service $1.5 \mathrm{~dB}$ to $3 \mathrm{~dB}$ improvement is observed for SAC-OCDM based implementation.

The BER estimated for the back-to-back case without fiber link is also shown for comparison. The bk - bk (back to back) response is determined by directly connecting the outputs of WDM MUX unit which is available at the CBS (Central Base Station) to the WDM DEMUX unit of the RAU

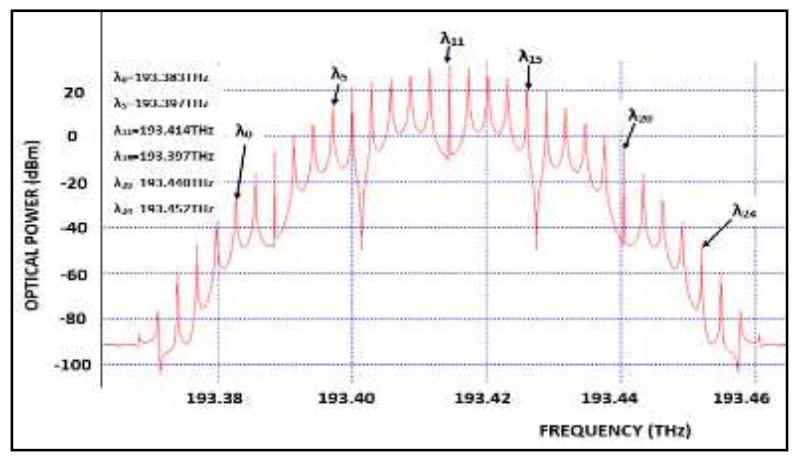

(a)

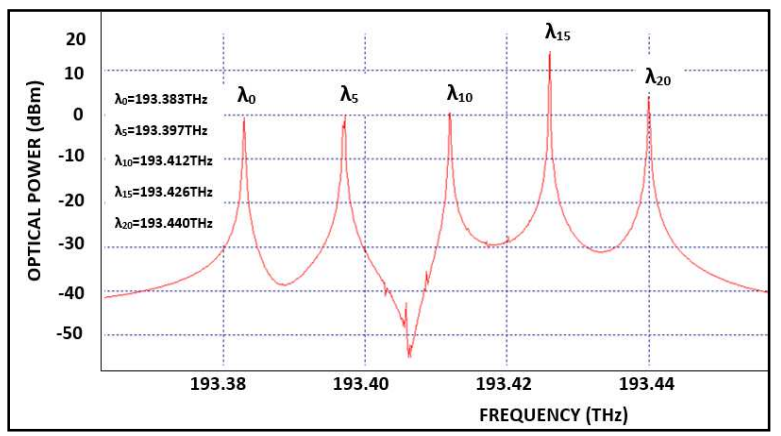

(b)

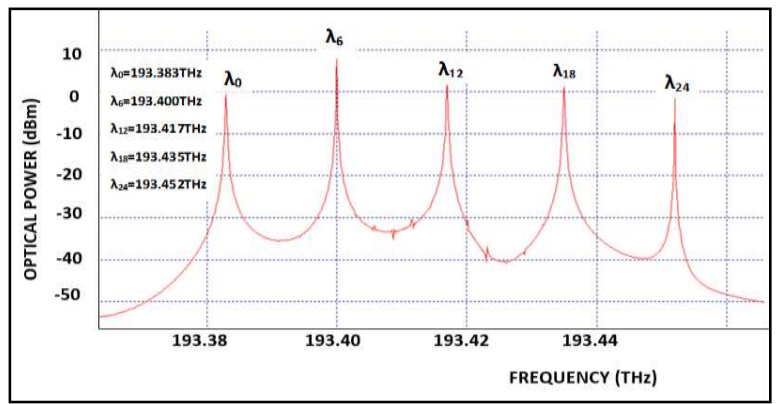

(c)

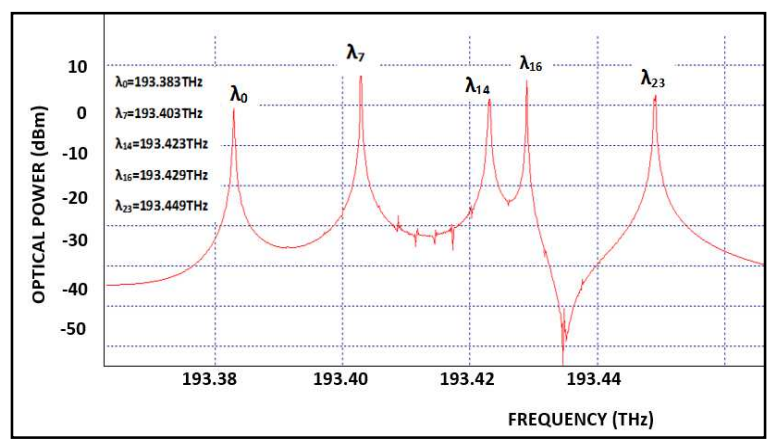

(d)

Fig. 3.

(a) Broadband coherent source emission spectrum (b) Spectral code pattern $\left(\lambda_{0} \lambda_{5} \lambda_{10} \lambda_{15} \lambda_{20}\right)$ for GSM signal (c) Spectral code pattern $\left(\lambda_{0} \lambda_{6} \lambda_{12} \lambda_{18} \lambda_{24}\right)$ for LTE signal (d) Spectral pattern $\left(\lambda_{0} \lambda_{7} \lambda_{14} \lambda_{16} \lambda_{23}\right)$ for WLAN signal 


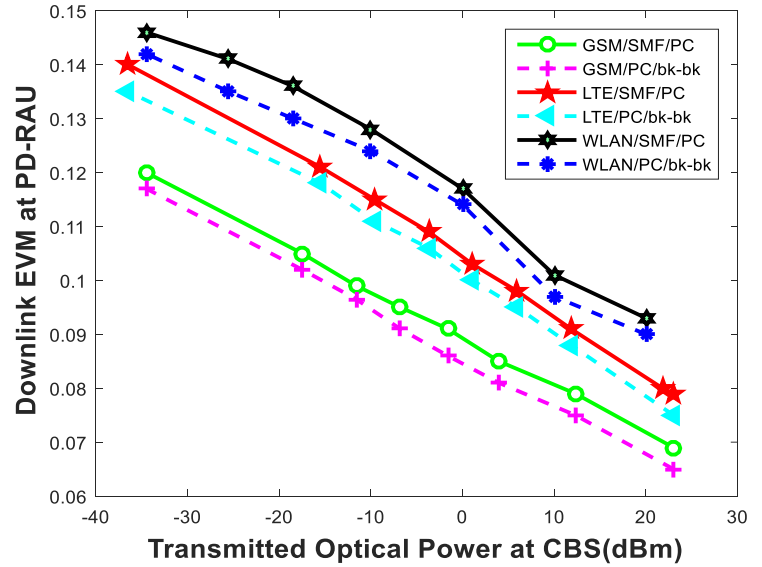

Fig.4. Comparison of the multiservice OCDM-PC of operator -1

The bk-bk connectivity eliminates the data transmission through fiber or else the analysis is carried out between CBS and RAU without fiber connectivity in the proposed downstream scenario of system.

\section{COMPARISON OF LINK POWER BUDGET, ENERGY EFFicienCy AND Electromagnetic Pollution EFFeCT ANALYSIS}

The link power budget analysis for the entire RoF link is carried out based on the method discussed in [40,41\&42] and compared for performance analysis with WDMA system. The factors that constitute a span loss of $26.44 \mathrm{~dB}$ [29] for the SAC-OCDM system include all the parameters listed in the Table V.

TABLE V

SPAN LOSS CALCULATION

\begin{tabular}{|l|l|}
\hline COMPONENT & LOSS(dB) \\
\hline FBG filter(10X0.5) & 5.0 \\
\hline Mux(5x1) & 2.2 \\
\hline De-Mux(1X5) & 2.2 \\
\hline $\begin{array}{l}\text { SMF step index cable at } \\
\text { 1550nm(25km*0.2dB/km) }\end{array}$ & 5.0 \\
\hline Splitter & 1.5 \\
\hline External Modulator(MZM) & 2.5 \\
\hline Coupler & 1.5 \\
\hline System Margin & 4.5 \\
\hline Fusion splicer(2X0.02) & 0.04 \\
\hline Dispersion margin & 1.0 \\
\hline SC connector(2X0.5) & 1.0 \\
\hline Total span loss & 26.44 \\
\hline
\end{tabular}

From the power budget calculations [40] for SACOCDM based services it is observed that the minimum optical power required for GSM service over fiber is nearly $15.41 \mathrm{dBm}$ at the CBS to achieve a BER of $10^{-4}$ in the user equipment (UE) with a fiber link distance of $25 \mathrm{~km}$ and a wireless link distance of $1 \mathrm{~km}$. Similarly, for other services namely, LTE, WLAN, Wi- Gig and LMDS, the minimum required optical power at CBS is found and the power budgets for all services are estimated and compared with the WDMA system as depicted in Fig. 5. (a). The detected power at RAU-
PD for each service as well as the received power at each UE is measured and compared with the WDMA system as shown in Fig. 5. (b), (c) \& (d).

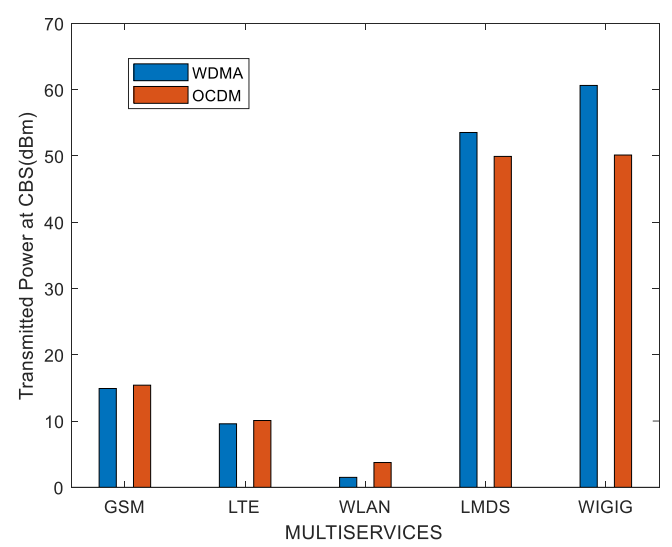

(a)

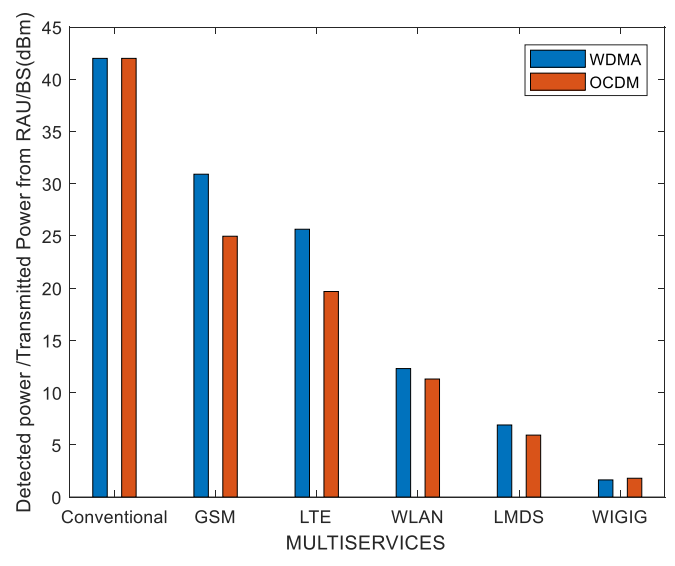

(b)

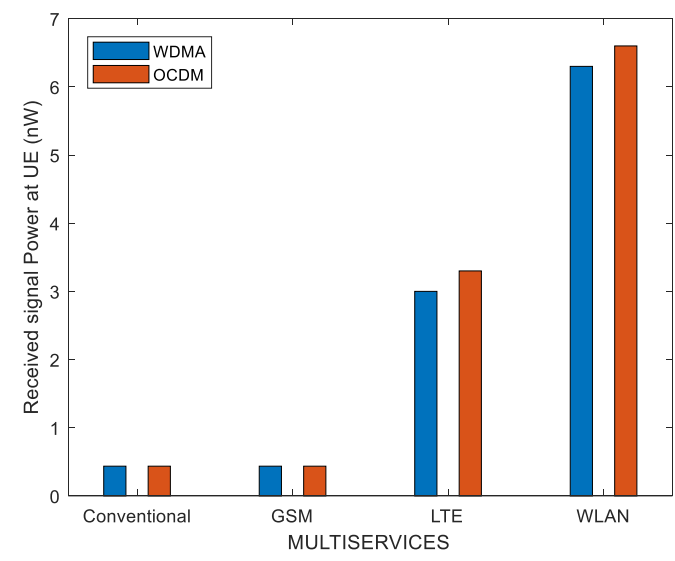

(c) 


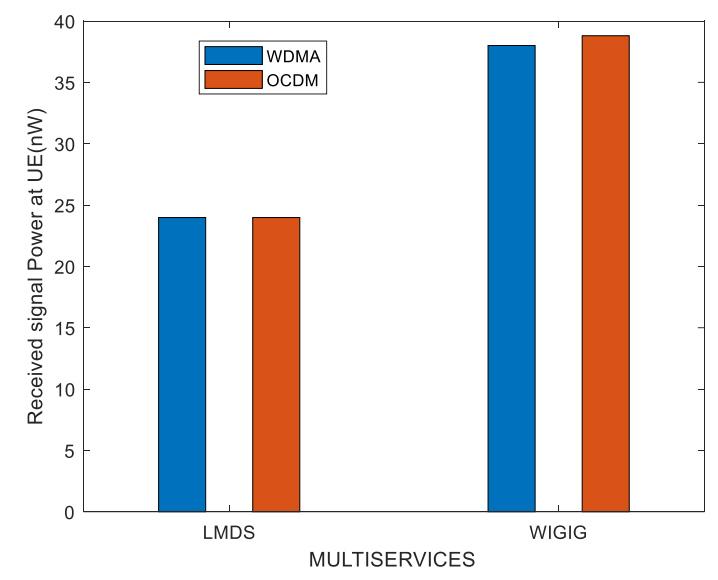

(d)

Fig. 5. (a) Comparison of the all 5 services at CBS for TX. Power (b) Comparison of the all 5 services at RAU for Detected Power (c) Comparison of the services at UE for received signal power (d) Comparison of the mmwave services at $\mathrm{UE}$ for received signal power

The percentage of total power consumed that is sent over air as useful power, the energy spent per bit in units of Joules/bit $(\mathrm{J} / \mathrm{b})$ and possible electromagnetic pollution impact distance are estimated and analyzed.

The minimum power that needs to be transmitted by the Remote Antenna Unit (RAU) for the RoF link so that the UE can detect the signal at the required BER level is calculated for all the services based on methodology implemented in the reference [40]. The individual comparison of each service based on prime codes based SAC-OCDM and WDMA are analyzed \& compared in the following sections.

In the case of the conventional wireless link a transmit power of $16 \mathrm{~W}$ is considered for a single data connection at $270 \mathrm{kbps}$ over a $200 \mathrm{kHz}$ channel bandwidth. All the above losses are considered and the total power consumption is arrived at $447 \mathrm{~W}$. The percentage of useful power works out to3.5\%. When the LTE service is operated over an SAC OCDM combine, the transmit power requirement at a single RAU is only $0.63 \mathrm{~W}$ and the total requirement to cover the region with 25 RAUs is $2.3 \mathrm{~W}$. The total power consumption at the RAUs is $17.9 \mathrm{~W}$. The percentage of useful power in this case works out to $12.87 \%$ which is significantly higher compared to the conventional single BS wireless scenario. The calculations carried out for the other services also show similar improvement as depicted in Fig. 6 (a) \& (b).

The energy spent per bit is calculated based on the grid power required at the BS/RAU for a single connection. Here again it is noted that the energy spent per bit in the conventional scenario is $1.44 \mathrm{~mJ} / \mathrm{b}$, whereas for the ARoF based transmission of LTE it is only $2.1 \mathrm{~nJ} / \mathrm{b}$. The corresponding values for the other services are also estimated and depicted in Fig. 7(a) \& (b). All the 5 services show significant reduction in the energy spent per bit. Hence by using ARoF link with RAUs, the total power consumption can be significantly reduced in spite of provisioning high data rates.

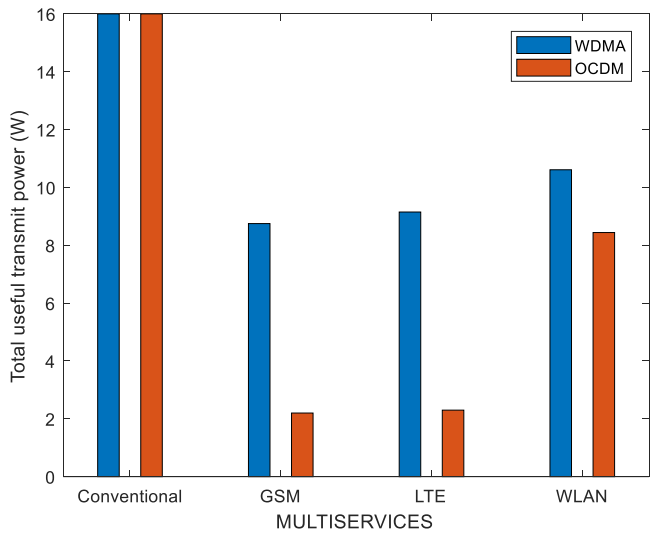

(a)

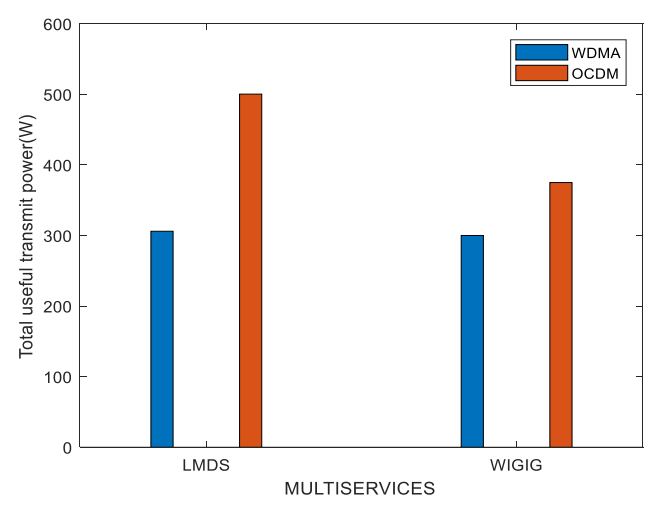

(b)

Fig. 6. (a) \& (b) Comparison of the services for total useful Power

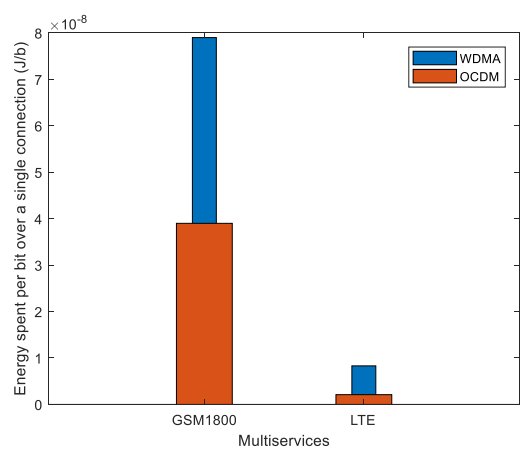

(a)

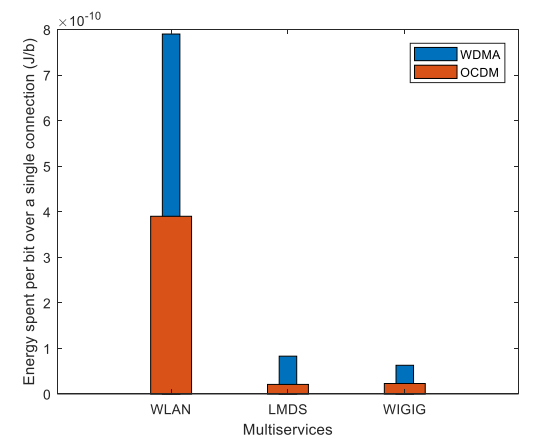

(b)

Fig. 7. (a) \& (b) Comparison of the services for Energy Spent per bit over a single connection 


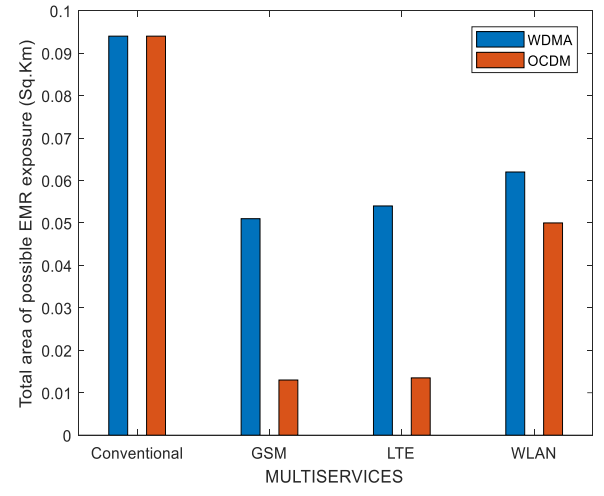

(a)

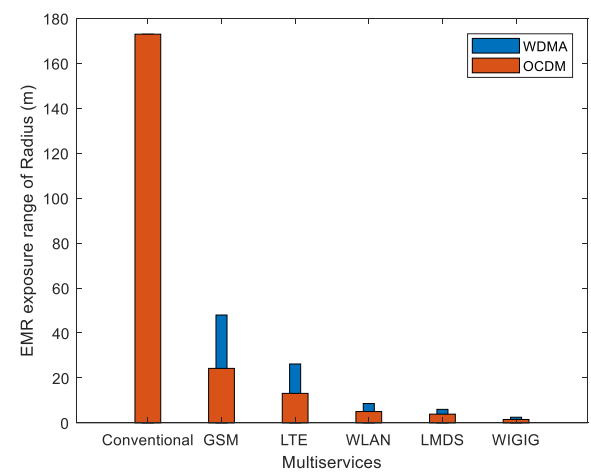

(b)

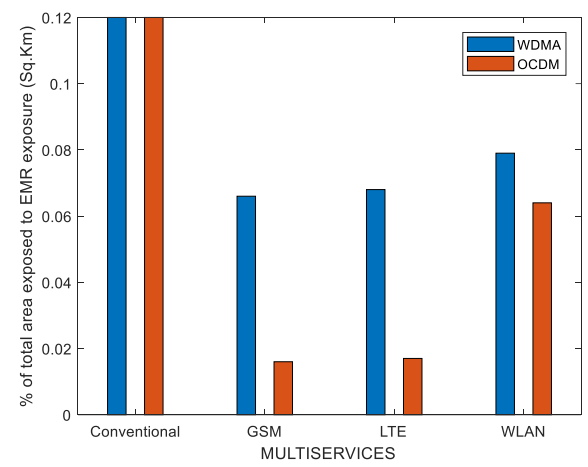

(c)

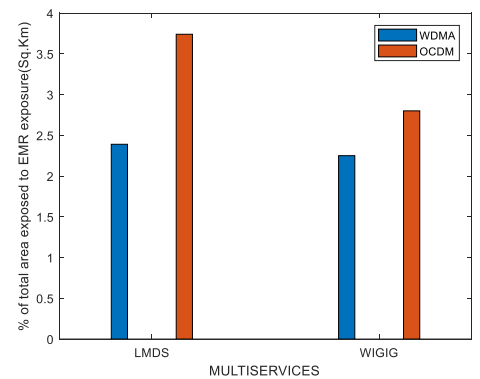

(d)

Fig. 8. (a) Comparison of the services for total area exposed to possible EMR exposure (b) Comparison of the services at UE for EMR exposure range of Radius (c) \& (d) Comparison of the services for \% of total area exposed to EMR exposure

The possible electromagnetic pollution is compared by estimating the distance from BS/RAU up to which the power spectral density is above the threshold limit of $170 \mathrm{~W} / \mathrm{km}^{2}$
[39]. The comparison of the 5 services over ARoF is done with that of a conventional wireless service and the possible area of EMR exposure for each service is identified and depicted in Fig. 8. (a).

The percentage of total area that has exposure beyond the threshold value is also compared for all the five ARoF services and the conventional scenario as depicted in Fig. 8. (b), (c) \& (d). It is observed that the ARoF based wireless services like GSM, LTE and WLAN expose less than $0.1 \%$ percentage of the total area to EMR compared to the conventional case where there is exposure for less than $1 \%$ of the total area. However, the millimeter wave services are observed to expose more than $2.5 \%$ of the total area to EMR. This is under the assumption that all the RAUs are actively transmitting $[39,40]$. This means that the data rates supported in the region by these services is enormous and could be traded off for reduced EMR exposure.

TABLE VI

COMPARISON OF OBSERVATIONS

\begin{tabular}{|c|c|c|c|c|}
\hline \multicolumn{2}{|c|}{ Scheme } & $\begin{array}{c}\% \text { of } \\
\text { Useful } \\
\text { power }\end{array}$ & $\begin{array}{c}\text { Energy } \\
\text { Spent per } \\
\text { bit } \\
\text { (Joules/bit) }\end{array}$ & $\begin{array}{l}\% \text { of total } \\
\text { area } \\
\text { exposed to } \\
\text { EMR }\end{array}$ \\
\hline \multicolumn{2}{|c|}{ Conventional Macrocell } & $3.5 \%$ & $1.44 \times 10^{-3}$ & $0.12 \%$ \\
\hline \multicolumn{2}{|c|}{$\begin{array}{c}\text { Cloud-RAN (CPRI } \\
\text { Interface) }\end{array}$} & $3.6 \%$ & $3.56 \times 10^{-7}$ & $0.067 \%$ \\
\hline \multirow{5}{*}{ MOMS-ARoF } & GSM & $12.79 \%$ & $3.15 \times 10^{-5}$ & $0.066 \%$ \\
\hline & LTE & $12.79 \%$ & $8.3 \times 10^{-9}$ & $0.068 \%$ \\
\hline & WLAN & $12.79 \%$ & $7.7 \times 10^{-10}$ & $0.079 \%$ \\
\hline & LMDS & $12.87 \%$ & $3.3 \times 10^{-11}$ & $2.39 \%$ \\
\hline & Wi-Gig & $12.86 \%$ & $2.05 \times 10^{-12}$ & $2.25 \%$ \\
\hline \multirow{5}{*}{ SAC- OCDM } & GSM & $12.87 \%$ & $7.93 \times 10^{-6}$ & $0.016 \%$ \\
\hline & LTE & $12.85 \%$ & $2.1 \times 10^{-9}$ & $0.017 \%$ \\
\hline & WLAN & $12.89 \%$ & $6.1 \times 10^{-10}$ & $0.064 \%$ \\
\hline & LMDS & $12.89 \%$ & $5.5 \times 10^{-11}$ & $3.74 \%$ \\
\hline & Wi-Gig & $12.86 \%$ & $2.6 \times 10^{-12}$ & $2.8 \%$ \\
\hline
\end{tabular}

This Table VI presents the contributions of the proposed analog RoF and Small Cell Network based different architectural approaches that address energy efficiency, network capacity and the electromagnetic pollution aspects. The discussed energy and EMR considerations consolidated in Table VI is a significant motivation to adopt SAC OCDM based wireless access, though the deployment cost may show some increase. However the increased cost is offset by the sharing of resources as well as by making the entire system flexible and future proof. It is observed that the ARoF based wireless services like GSM, LTE and WLAN expose less than $0.1 \%$ percentage of the total area to EMR 


\section{CONCLUSION}

Multi-operator multi-service OCDM based Spectrally Amplitude Encoded Analog Radio over Fiber (SAC-OCDM) front-haul for a small cell configuration is suggested as a solution to reduce the system cost by employing suitable codes for multiple services instead of allocating wavelengths. Since OCDM can provide connections on demand to simultaneously employ the same lambda channels in appropriately coded forms, different services can be multiplexed at the same wavelengths through unique spectral signature patterns. Exclusive patterns based on unique Prime codes are assigned for each service like GSM, LTE and WLAN, encoded and multiplexed at the same wavelengths. The Comparison results of Energy efficiency and electromagnetic pollution impact for the services confirm that the proposed architecture is capable to meet the $5 \mathrm{G}$ fronthaul challenges.

\section{REFERENCES}

1. Alcatel-Lucent, "Light Radio network: A new wireless experience," White Paper, 2012.

2. Nokia Outdoor 3G/LTE Small Cells Deployment Strategy: "The Race to the Pole"-white paper- http://networks.nokia.com

3. John Naylon, Breaking barriers for small cell networks, 2013- white paper - www.cbnl.com

4. Ashwin Amanna, Green Communications - Annotated Literature Review and Research Vision-Wireless @ VirginTech, 2011.

5. Ziaul Hasan et al., Green Cellular Networks: A Survey, Some Research Issues and Challenges, Communications Surveys \& Tutorials, IEEE, vol. 13, issue 4, pp. 524-540, 2011.

6. Luis M Correia, Dietrich Zeller \& Oliver Blume, 'Challenges and enabling technologies for energy aware mobile radio networks', IEEE Communications Magazine, vol. 48, no. 11, pp. 66-72, 2010.

7. Girish Kumar, Report on cell tower radiation, DOT, Delhi, IIT Bombay Government of India Ministry of Communications \& Information Technology Department of Telecommunications .Report of the interministerial committee On EMF radiation. www.dot.gov.in / miscellaneous / IMC\%20 Report / IMC\%20, 2010,

8. Sumit Katiyar RK Jain \& Agrawal, NK, R.F. Pollution Reduction in Cellular Communication, 2010

9. Vodafone group plc., Sustainability report, 2010, http://www. vodafone.com /content/index/about/sustainability.

10.Brindha, S \& Meenakshi, M, 'Radio over fiber system architecture: a boon to meet future energy and Pollution challenges', Optoelectronics and advanced materials - Rapid Communications, vol. 9, 2015, pp. 855-864.

11.Jakob Hoydis, Mari Kobayashi, and Merouane Debbah, , 'Green SmallCell Networks', IEEE Vehicular Technology Magazine, vol.16,pp.37-43, 2011.

12.OBSAI specification, 2013. [Online], www.obsai.com,

13.NI White paper, Efficient Testing of wireless radio equipment including $R F$ and CPRI, Published online May 2017.

14.CPRI Interface Specification, v. 6.1, Jul. 1, 2014

15.Cheng Liu, Lian Zhang \& Ming Zhu, 'A Novel Multi-Service Small-Cell Cloud Radio Access Network for Mobile Backhaul and Computing Based on Radio-Over-Fiber Technologies', Journal of light Wave technology vol. 31, p. 2869, 2013.

16.Zhigang Cao \& Yasheng Qian, The principle of modern telecommunication. Tsinghua University Press, 1992.

17.Paul R Prucnal, Optical Code Division Multiple Access-Fundamental and Applications. CRC Press, Taylor \& Francis, 2006.

18.Jian-Guo Zhang, 'Design of Integrated Services Digital Broadcasting Systems Using Multirate Optical Fiber Code-Division Multiplexing'- IEEE Trans. on Broadcasting, vol. 45, no. 1, 1999,pp. 283- 293.
19. Yang, GC \& Kwong, WC, 'Design of multilength optical orthogonal codes for optical code-division multiple-access multimedia networks. IEEE Trans. on Communications, vol. 50, no. 8, 2002, pp. 1258-1265.

20.Katsutoshi Tsukamoto, Takeshi Higashino, Takashi Nakanishi \& Shozo Komaki, 'Direct Optical Switching Code-Division Multiple-Access System for Fiber-Optic Radio Highway Networks'- IEEE/OSA Journal of Lightwave Technology,vol.21,no.12,2003,pp.3209-3220.

21.Shalaby, HMH, Synchronous fiber-optic CDMA systems with interference estimators IEEE/OSA Journal of Lightwave Technology, vol. 17, no. 11, 1999, pp. 2268-2275

22.Shalaby, HMH, Shiraz, HG \& Zou Wei, 'Modified Quadratic Congruence Codes for Fiber Bragg-Grating-Based Spectral-Amplitude-Coding Optical CDMA Systems', Journal of Lightwave Technology, vol. 19, no. 9, 2001.

23.Ivan A Avrutsky, Xu, JM, 'Multi wavelength Diffraction and Apodization using binary superimposed gratings', IEEE photonics technology letters, vol. 10 , no. 6,1998 , pp. 839-841.

24.Wei Huang, Mohamed HM Nizam, Ivan Andonovic \& Tur, M, 'Coherent Optical CDMA (OCDMA) Systems Used for High-Capacity Optical Fiber Networks-System Description, OTDMA Comparison, and OCDMA/WDMA Networking', Journal of Lightwave Technology, vol. 18, no. 6, 2000.

25.Yang, GC \& Wing C Kwong, 'Performance analysis of optical CDMA with prime codes'. IEE Electronics Letters, vol. 31, no.7, 1995,pp. 569-570.

26.Meenakshi, M \& Andonovic, I, 'Effect of Physical Layer Impairments on SUM and AND detection strategies for 2D-Optical CDMA', IEEE Photonics Technology Letters, vol. 17, no. 4, 2005.

27.Meenakshi, M \& Andonovic, I, 'Code-Based All Optical Routing Using Two-Level Coding', Journal of Lightwave Technology, vol. 24, no. 4, 2006.

28.Kitayama, K, Xu Wang \& Naoya Wada, 'OCDMA Over WDM PONSolution Path to Gigabit Symmetric FTTH', Journal of Lightwave Technology, vol. 24, no. 4, 2006.

29. Agarwal, GP, Fiber Optic communication Systems, Third Edition, John Wiley and Sons, Inc., New York ISBN: 978-81-265-1386-4, 2010,pp.284300

30.Hongxi-Yin, Optical Code Division Multiple access Communication Networks, Tsinghua University Press, 2008.

31.RSOFT OPTSIM V2015.06 User Manual, USA, 2015. Web: http://optics.synopsys.com.

32.Akihiko Hirata \& Hiroyuki Takahashi, 'Transmission characteristics of $120 \mathrm{GHz}$ band wireless link Using Radio on Fiber technologies', Journal of LightwaveTechnology,vol.26,no.15,2008,pp.2338-2344.

33.Tomohiro Taniguchi, Naoya Sakurai \& Hideaki Kimura, 'Technical trends in millimeter wave band Radio-on-Fiber access systems', PIERS Proceedings, Beijing, 2009,pp. 24-27.

34.Rappaport, TS, Wireless communications: principles and practice, Prentice Hall, USA, 2002,pp.28-45.

35.David Tse \& Pramod Viswanath, Fundamentals of Wireless Communication, Cambridge University Press, Singapore, 2007,pp.123-125.

36.Gerd keiser, Optical fiber Communication, 4th edition Tata Mcgraw Hill, India, and ISBN: 978-1-25-900687-6, 2013.

37.www.thefoa.org/tech/ref/basic/test.html.

38. Oliver Arnold et al., Power consumption modeling of different base station types in heterogeneous Cellular networks in Proc. of $19^{\text {th }}$ Future Network \& Mobile Summit, Italy, 2010.

39. Venkatapathy, P, Jena, J \& Jandhyala, A, 'Electromagnetic Pollution Index - A Key Attribute of Green Mobile Communications', Green Technologies Conference IEEE, pp. 19-20, 2012.

40. Brindha Saminathan, Ilavarasan Tamilarasan \& Meenakshi Murugappan, 'Energy and electromagnetic pollution considerations in ARoF-based multioperator multi-service systems', Photonic Network Communications, Springer US Publisher, DOI: 10.1007/s11107-017-0686-z, Online ISSN: 1572-8188, Print ISSN: 1387-974X, vol. 34, pp. 221-240, Oct., 2017.

41. Ai-Sheng Chen, Yi-Chang Chen and Long-Guang Liao, (2018) 'Advancing High-Speed Transmissions over OCDMA Networks by Employing an Intelligently Structured Receiver for Noise Mitigation'-Applied Sciences, 8, 2408; doi:10.3390/app8122408.

42. Waqas A. Imtiaz, Affaq Qamar, Atiq Ur Rehman, Haider Ali, Adnan Rashid Chaudhry and Javed Iqbal, (2017) 'Design and analysis of Self healing tree based hybrid spectral Amplitude coding OCDMA system'-Security and Communication Networks-Hindawi Volume 2017, Article ID 2524513, 12 pages, doi.org/10.1155/2017/2524513 


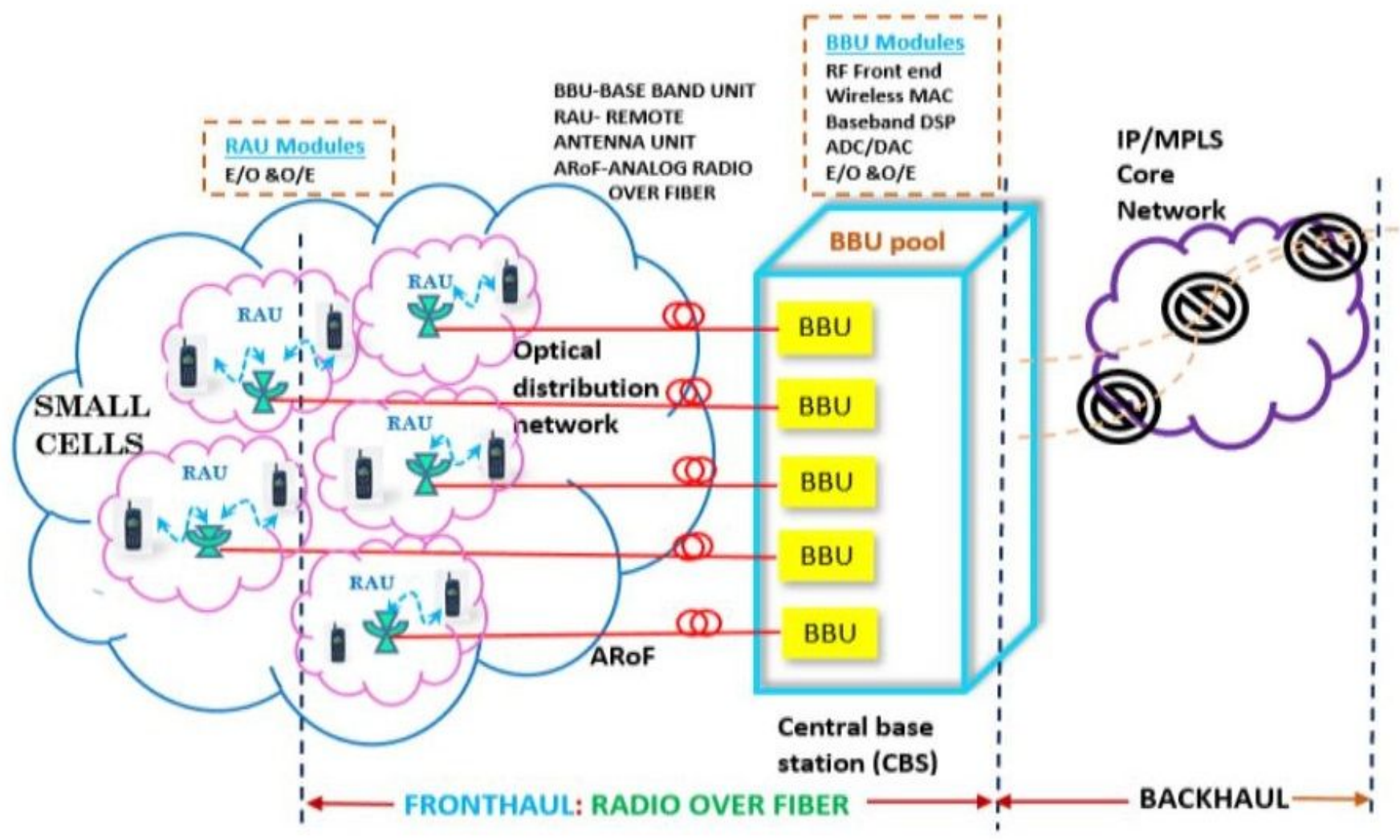

Figure 1

Architecture of Small cell based Cloud - RoF 

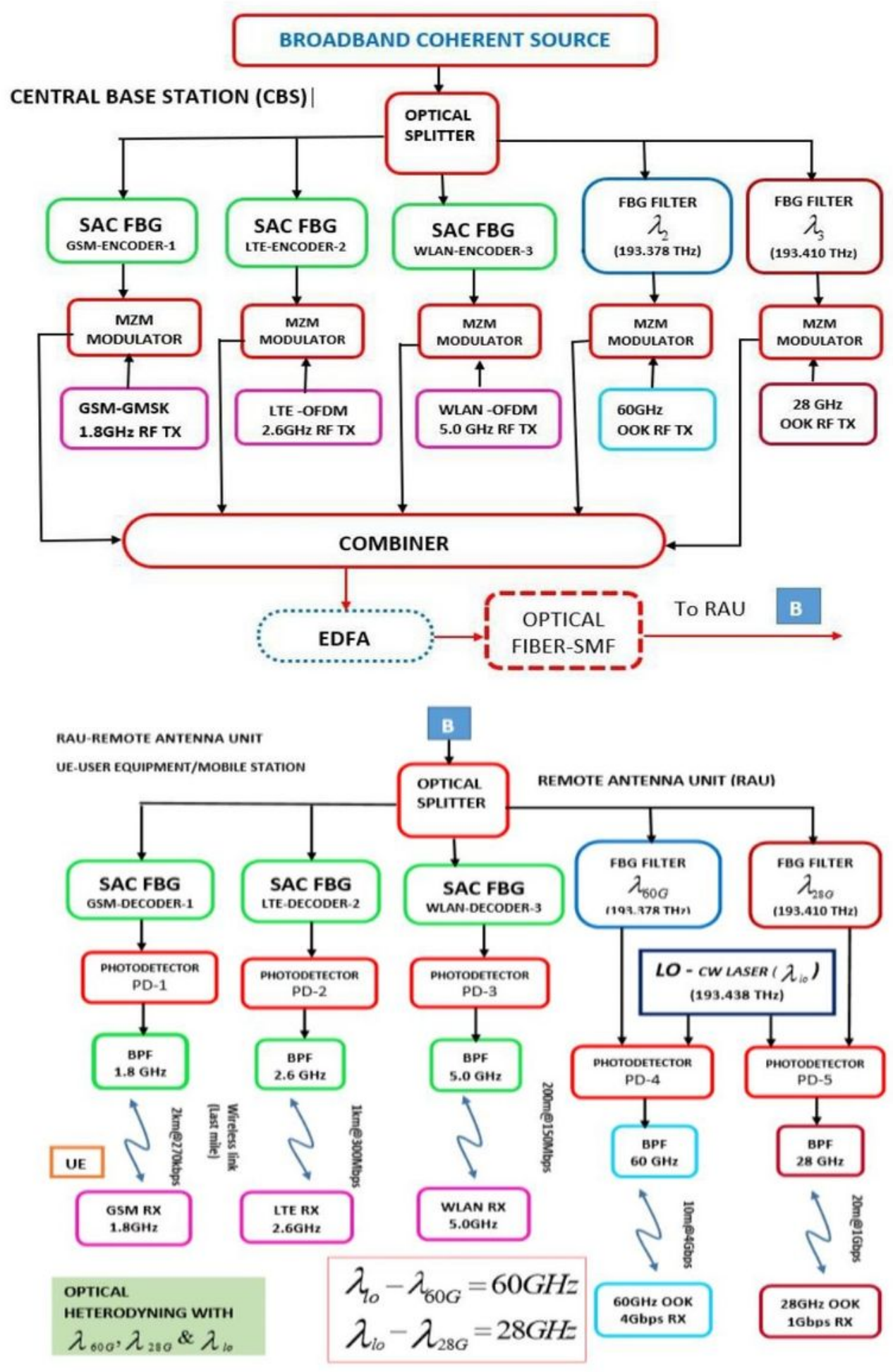

Figure 2

System block diagram of SAC -OCDM 


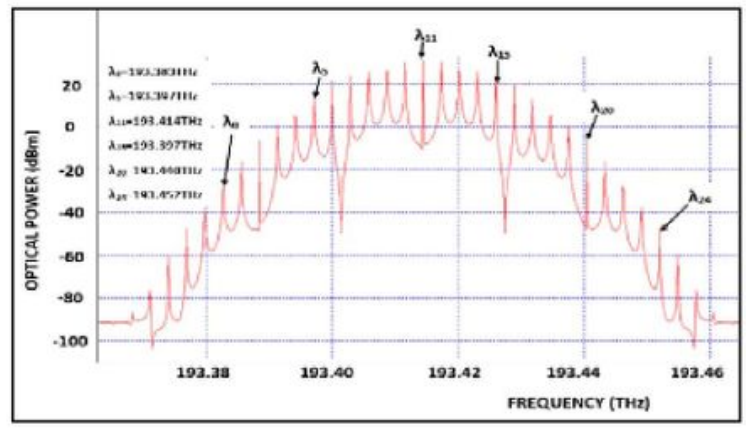

(a)

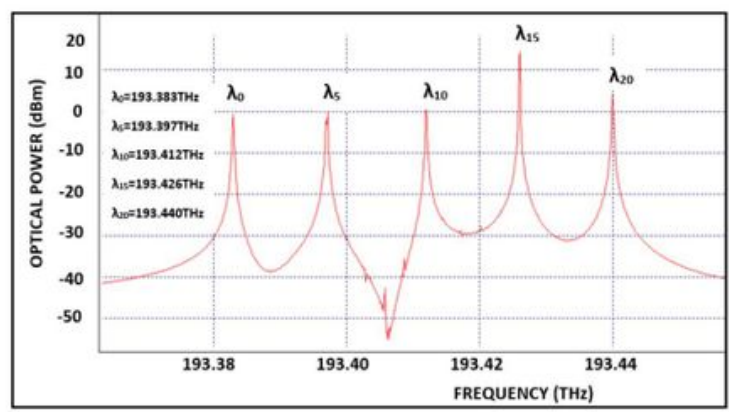

(b)

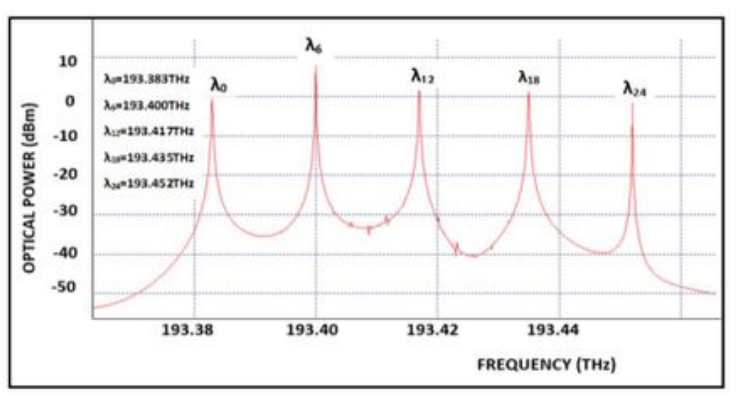

(c)

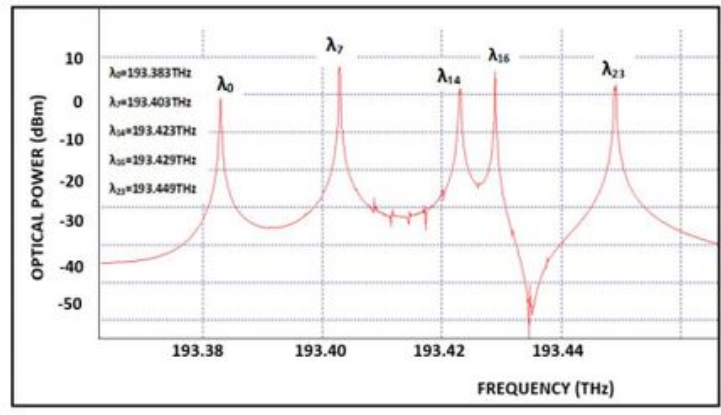

(d)

Figure 3

Please see the Manuscript PDF file for the complete figure caption 


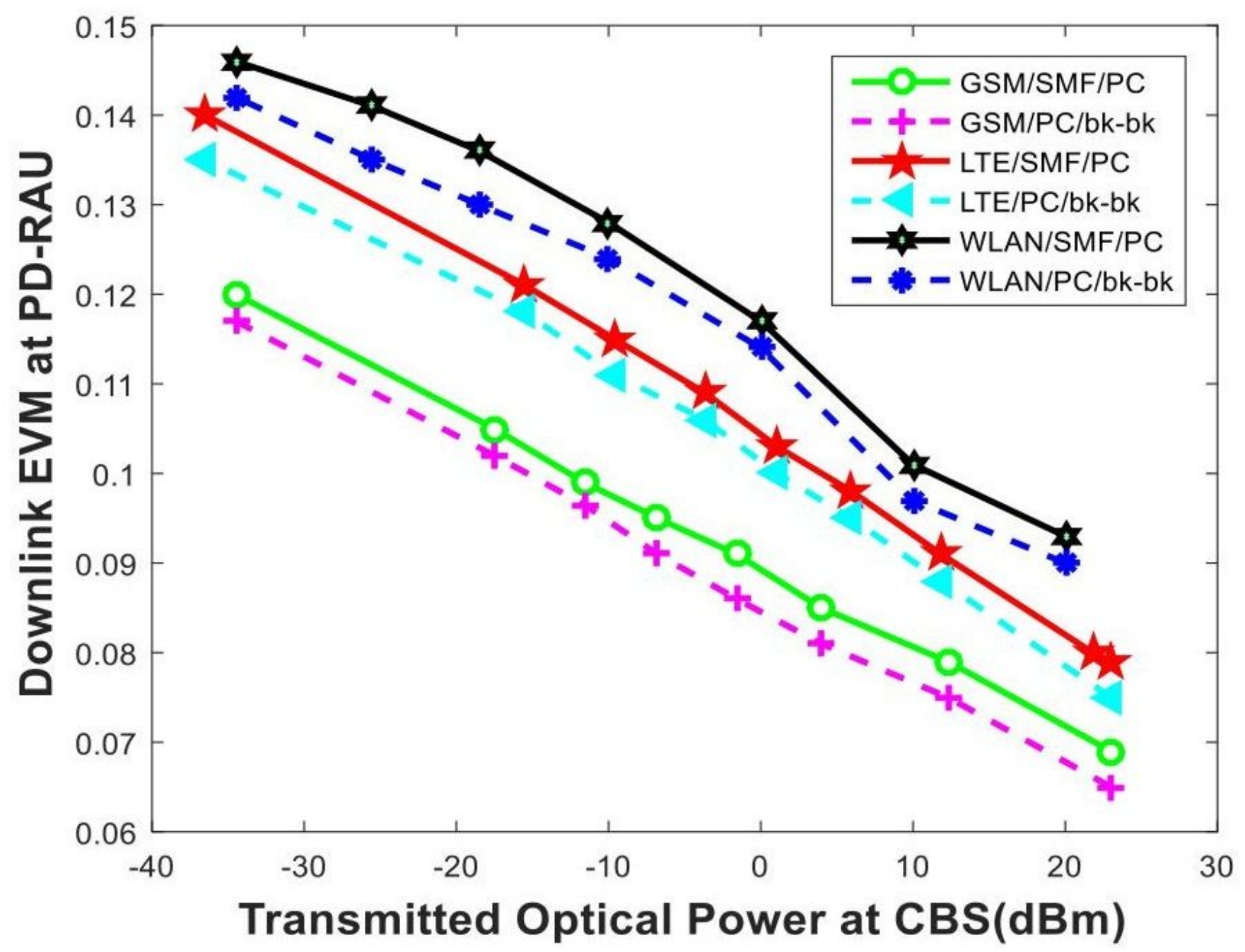

Figure 4

Comparison of the multiservice OCDM-PC of operator - 1 


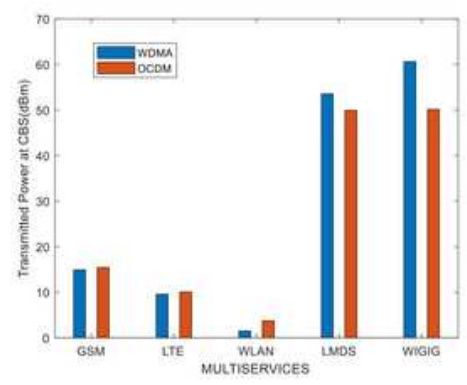

(a)

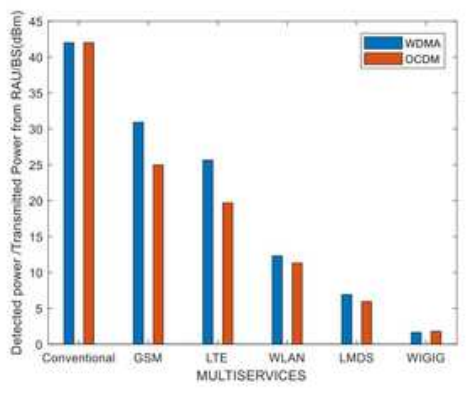

(b)

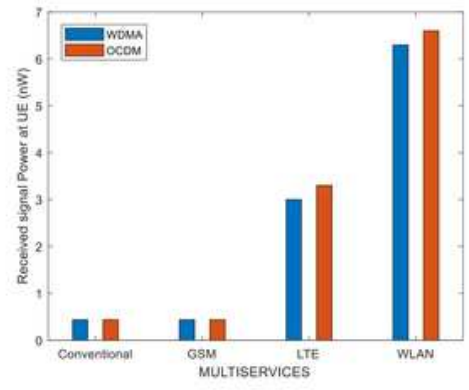

(c)

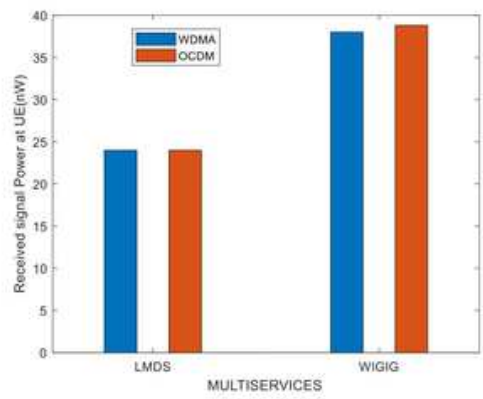

(d)

Figure 5

(a) Comparison of the all 5 services at CBS for TX. Power (b) Comparison of the all 5 services at RAU for Detected Power (c) Comparison of the services at UE for received signal power (d) Comparison of the mmwave services at UE for received signal power 


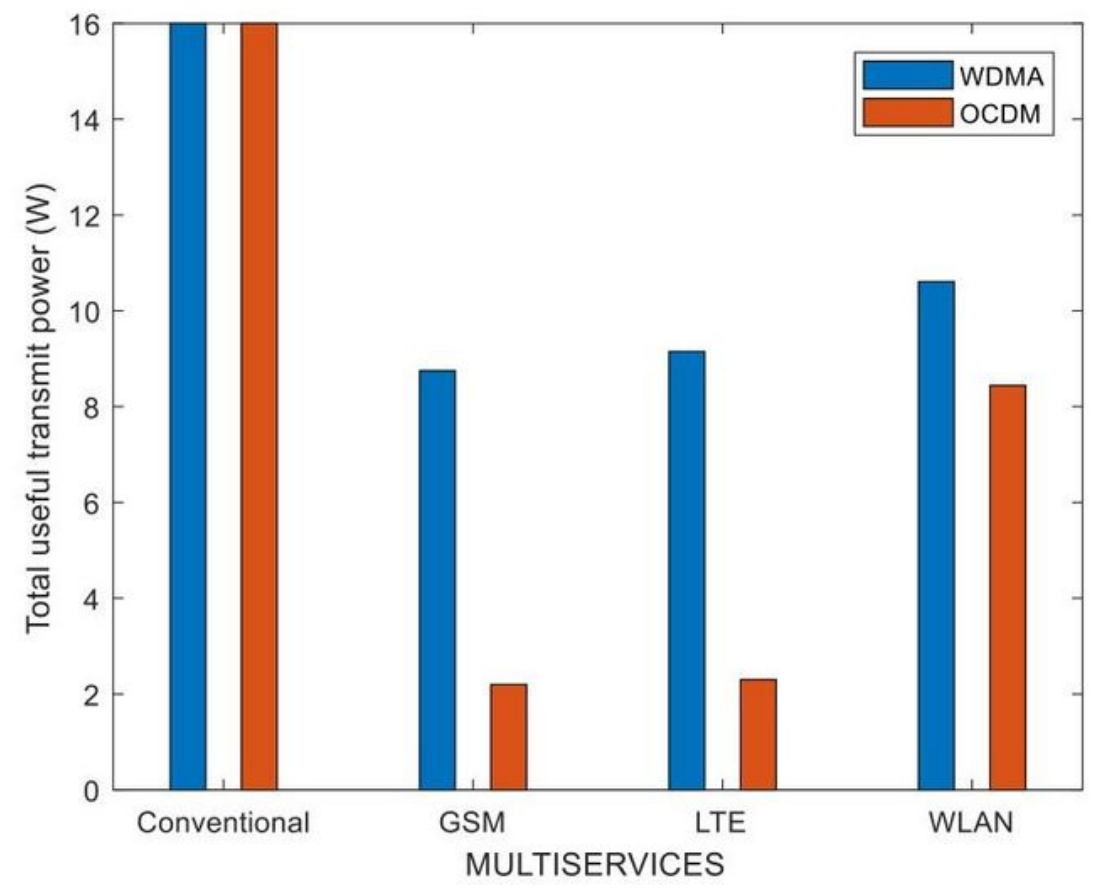

(a)

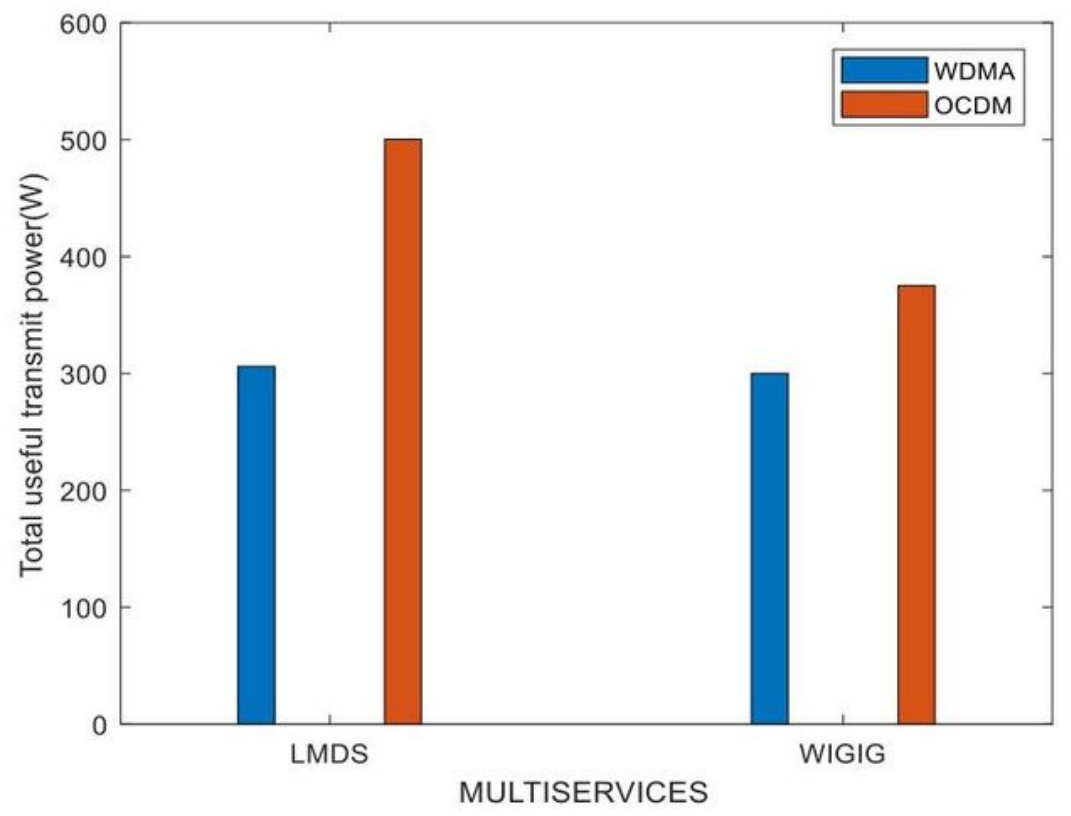

(b)

Figure 6

(a) \& (b) Comparison of the services for total useful Power 


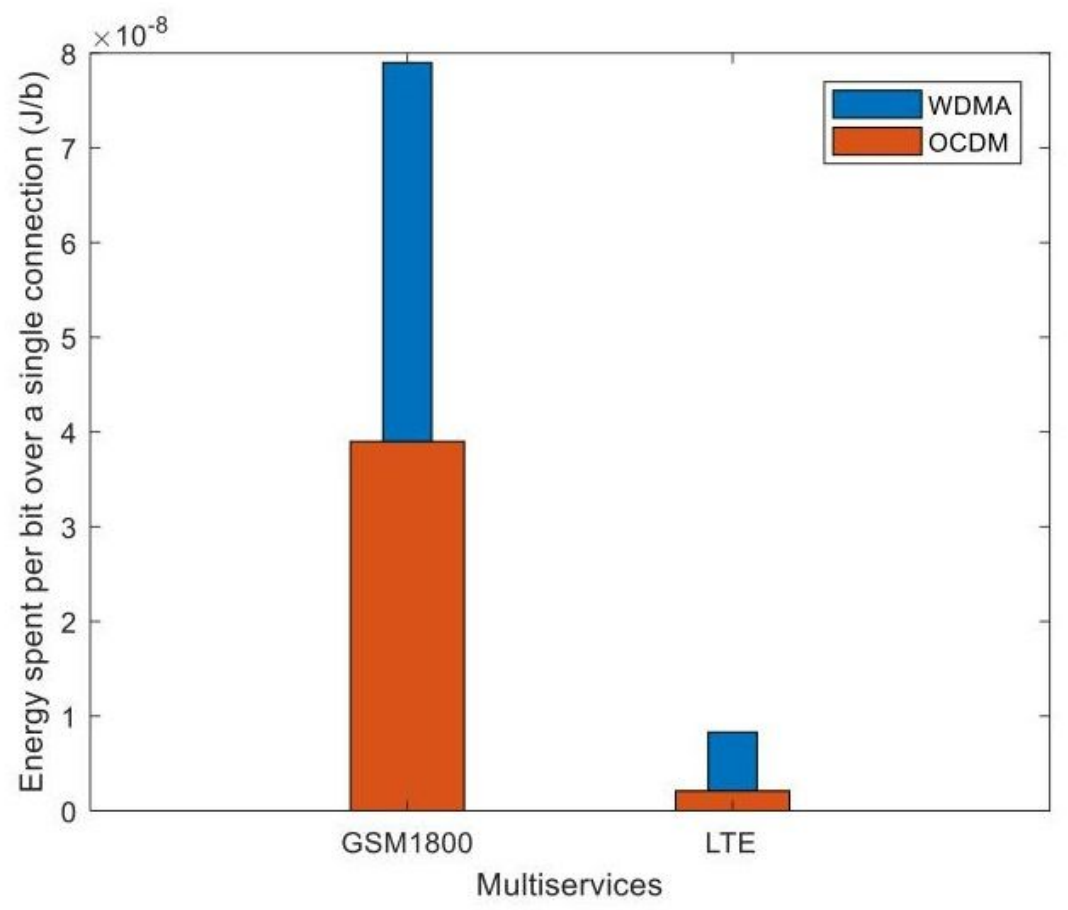

(a)

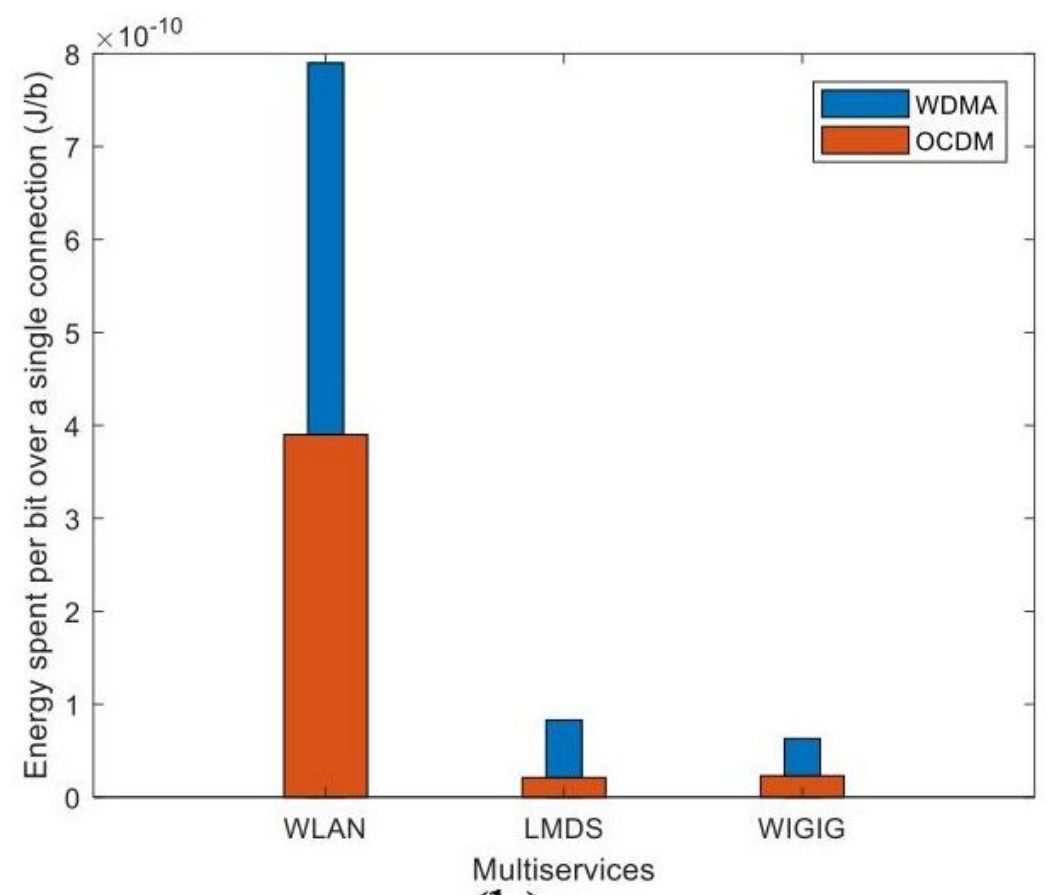

(b)

Figure 7

(a) \& (b) Comparison of the services for Energy Spent per bit over a single connection 


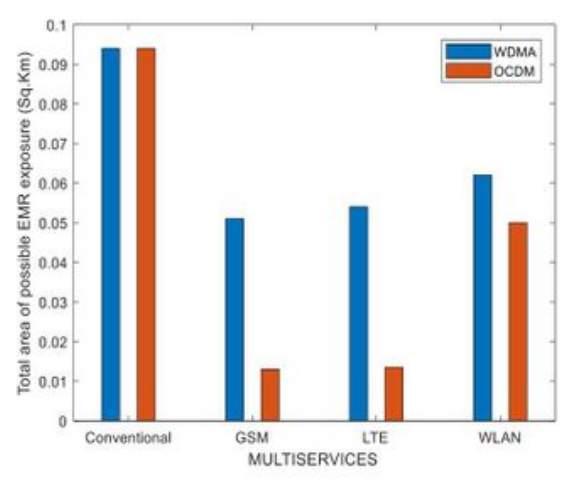

(a)

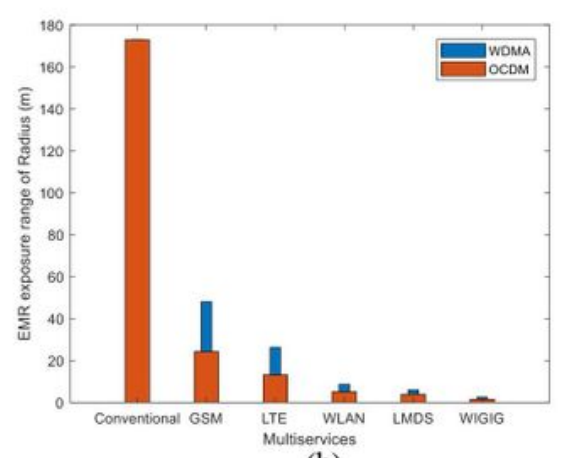

(b)

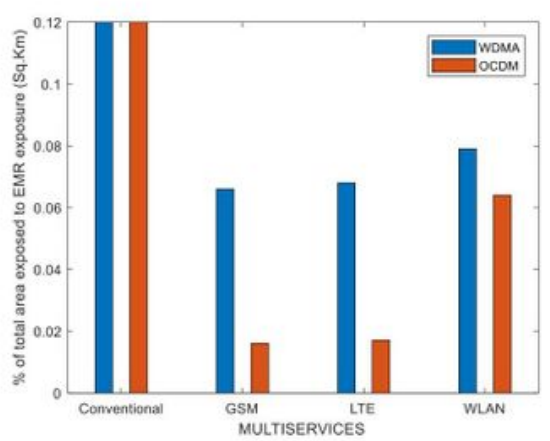

(c)

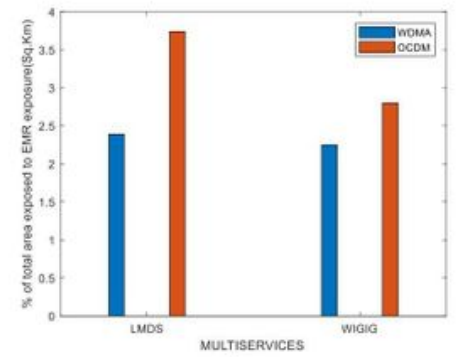

(d)

\section{Figure 8}

(a) Comparison of the services for total area exposed to possible EMR exposure (b) Comparison of the services at UE for EMR exposure range of Radius (c) \& (d) Comparison of the services for \% of total area exposed to EMR exposure 